$$
\begin{aligned}
& \sum_{\text {Colleg }}^{\text {inspin }} \\
& \text { AP } \\
& \text { BIOLOGY } \\
& \text { Curriculum Framework } \\
& \text { 2012-2013 }
\end{aligned}
$$




\title{
The College Board
}

\author{
About the College Board \\ The College Board is a mission-driven not-for-profit organization that connects students \\ to college success and opportunity. Founded in 1900, the College Board was created to \\ expand access to higher education. Today, the membership association is made up of more \\ than 5,900 of the world's leading educational institutions and is dedicated to promoting \\ excellence and equity in education. Each year, the College Board helps more than seven \\ million students prepare for a successful transition to college through programs and \\ services in college readiness and college success - including the SAT ${ }^{\circledast}$ and the Advanced \\ Placement Program ${ }^{\circledast}$. The organization also serves the education community through \\ research and advocacy on behalf of students, educators and schools. \\ For further information, visit www.collegeboard.org. \\ (C) 2011 The College Board. College Board, Advanced Placement Program, AP, SAT \\ and the acorn logo are registered trademarks of the College Board. inspiring minds \\ is a trademark owned by the College Board. All other products and services may be \\ trademarks of their respective owners. \\ Published by the College Board in February 2011.
}




\section{Contents}

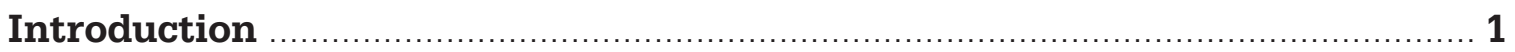

The Emphasis on Science Practices

Overview of the Concept Outline

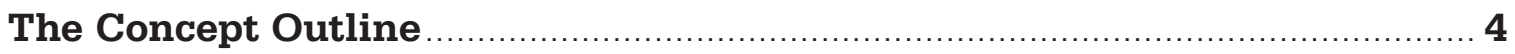

Big Idea 1: The process of evolution drives the diversity and unity of life. ................ 4

Big Idea 2: Biological systems utilize free energy and molecular building blocks to grow, to reproduce and to maintain dynamic homeostasis.

Big Idea 3: Living systems store, retrieve, transmit and respond to information essential to life processes.

Big Idea 4: Biological systems interact, and these systems and their interactions possess complex properties.

\section{Science Practices for AP $^{\circledast}$ Biology}

Science Practice 1: The student can use representations and models to communicate scientific phenomena and solve scientific problems.

Science Practice 2: The student can use mathematics appropriately.

Science Practice 3: The student can engage in scientific questioning to extend thinking or to guide investigations within the context of the AP course.

Science Practice 4: The student can plan and implement data collection strategies appropriate to a particular scientific question.

Science Practice 5: The student can perform data analysis and evaluation of evidence.

Science Practice 6: The student can work with scientific explanations and theories.

Science Practice 7: The student is able to connect and relate knowledge across various scales, concepts and representations in and across domains.

References

Appendix. 


\section{Introduction}

Given the speed with which scientific discoveries and research continuously expand scientific knowledge, many educators are faced with the challenge of balancing breadth of content coverage with depth of understanding.

The revised $\mathrm{AP}^{\circledast}$ Biology course addresses this challenge by shifting from a traditional "content coverage" model of instruction to one that focuses on enduring, conceptual understandings and the content that supports them. This approach will enable students to spend less time on factual recall and more time on inquiry-based learning of essential concepts, and will help them develop the reasoning skills necessary to engage in the science practices used throughout their study of AP Biology.

To foster this deeper level of learning, the breadth of content coverage in AP Biology is defined in a way that distinguishes content essential to support the enduring understandings from the many examples or applications that can overburden the course. Illustrative examples are provided that offer teachers a variety of optional instructional contexts to help their students achieve deeper understanding. Additionally, content that is outside the scope of the course and exam is also identified.

Students who take an AP Biology course designed using this curriculum framework as its foundation will also develop advanced inquiry and reasoning skills, such as designing a plan for collecting data, analyzing data, applying mathematical routines, and connecting concepts in and across domains. The result will be readiness for the study of advanced topics in subsequent college courses - a goal of every AP course.

\section{The Emphasis on Science Practices}

A practice is a way to coordinate knowledge and skills in order to accomplish a goal or task. The science practices enable students to establish lines of evidence and use them to develop and refine testable explanations and predictions of natural phenomena. Because content, inquiry and reasoning are equally important in AP Biology, each learning objective described in the concept outline combines content with inquiry and reasoning skills described in the science practices.

The science practices that follow the concept outline of this framework capture important aspects of the work that scientists engage in, at the level of competence expected of AP Biology students. AP Biology teachers will see within the learning objectives how these practices are effectively integrated with the course content, and will be able to design instruction with these practices in mind. 


\section{Overview of the Concept Outline}

The key concepts and related content that define the revised AP Biology course and exam are organized around a few underlying principles called the big ideas, which encompass the core scientific principles, theories and processes governing living organisms and biological systems. For each of the big ideas, enduring understandings, which incorporate the core concepts that students should retain from the learning experience, are also identified.

Each enduring understanding is followed by statements of the essential knowledge necessary to support it. Unless otherwise specified, all of the details in the outline are required elements of the course and may be included in the AP Biology Exam. To help teachers distinguish content that is essential to support the enduring understandings from the many possible examples and applications that can overburden a course - and to see where important connections exist among the different content areas - particular content components are emphasized as follows:

- Underlying content that must also be taught in order for students to achieve an understanding of a particular required concept is specified in detail. These additional underlying content components are listed numerically under the required concept and are always preceded by the following preamble: "Evidence of student learning is a demonstrated understanding of each of the following:"

- Illustrative examples are suggested contexts for instructional purposes and are not required content components of the course. A student's knowledge of these contexts will not be assessed on the AP Biology Exam. Nevertheless, the illustrative examples provide suggestions for teachers that will support student understanding of a particular required concept. Illustrative examples can also lend themselves to case studies or project-based lessons. Teachers are free to use their own examples. The choice of which illustrative example to use (from those that are listed or elsewhere) should be selected according to the availability of data, regional relevance, interests of the students and expertise of the instructor. Illustrative examples are designated as bulleted statements and are always preceded by the following preamble: "To foster student understanding of this concept, instructors can choose an illustrative example such as:"

- Exclusion statements define content, or specific details about the content, that do not need to be included in the course because teaching this level of detail does not foster students' conceptual understanding. These details will not be assessed on the AP Biology Exam. Exclusion statements are denoted as shown in this example:

X Memorization of the names, molecular structures and specific effects of all plant hormones are beyond the scope of the course and the AP Exam.

Note: While illustrative examples and excluded content will not be assessed on the AP Biology Exam, they may be provided in the body of exam questions as background information for the concept and science practice(s) being assessed. 
- Concept and content connections are denoted in brackets (e.g., [See also 1.B.1]) and indicate where an overlap, or further clarification or application, of concepts and content exists. For example, the statement in 2.D.2.a.: "Continuity of homeostatic mechanisms reflects common ancestry, while changes may occur in response to different environmental conditions" is connected to the concepts and supporting content in 1.B.1, relating to how organisms share many conserved core processes and features that evolved and are widely distributed among organisms today.

- Learning objectives provide clear and detailed articulation of what students should know and be able to do. Each learning objective is designed to help teachers integrate science practices with specific content, and to provide them with clear information about how students will be expected to demonstrate their knowledge and abilities. Learning objectives are numbered to correspond with each Big Idea (e.g., LO 1.1). Alignment of the learning objectives to the science practices (detailed in Section III) is denoted in brackets. For example, in the third learning objective under 1.A.1: "The student is able to apply mathematical methods to data from a real or simulated population to predict what will happen to the population in the future. [See SP 2.2]," the bracketed reference points to this science practice: "2.2 The student can apply mathematical routines to quantities that describe natural phenomena." 


\section{The Concept Outline}

\section{Big Idea 1: The process of evolution drives the diversity and unity of life.}

Evolution is a change in the genetic makeup of a population over time, with natural selection its major driving mechanism. Darwin's theory, which is supported by evidence from many scientific disciplines, states that inheritable variations occur in individuals in a population. Due to competition for limited resources, individuals with more favorable variations or phenotypes are more likely to survive and produce more offspring, thus passing traits to future generations.

In addition to the process of natural selection, naturally occurring catastrophic and human induced events as well as random environmental changes can result in alteration in the gene pools of populations. Small populations are especially sensitive to these forces. A diverse gene pool is vital for the survival of species because environmental conditions change. Mutations in DNA and recombinations during meiosis are sources of variation. Human-directed processes also result in new genes and combinations of alleles that confer new phenotypes. Mathematical approaches are used to calculate changes in allele frequency, providing evidence for the occurrence of evolution in a population.

Scientific evidence supports the idea that both speciation and extinction have occurred throughout Earth's history and that life continues to evolve within a changing environment, thus explaining the diversity of life. New species arise when two populations diverge from a common ancestor and become reproductively isolated. Shared conserved core processes and genomic analysis support the idea that all organisms - Archaea, Bacteria, and Eukarya, both extant and extinct - are linked by lines of descent from common ancestry. Elements that are conserved across all three domains are DNA and RNA as carriers of genetic information, a universal genetic code and many metabolic pathways. Phylogenetic trees graphically model evolutionary history and "descent with modification." However, some organisms and viruses are able to transfer genetic information horizontally.

The process of evolution explains the diversity and unity of life, but an explanation about the origin of life is less clear. Experimental models support the idea that chemical and physical processes on primitive Earth could have produced complex molecules and very simple cells. Under laboratory conditions, complex polymers and self-replicating molecules can assemble spontaneously; thus, the first genetic material may not have been DNA, but short sequences of self-replicating RNA that may have served as templates for polypeptide synthesis. Protobiontic formation was most likely followed by the evolution of several primitive groups of bacteria that used various means of obtaining energy. Mutually beneficial associations among ancient bacteria are thought to have given rise to eukaryotic cells. 


\section{Enduring understanding 1.A: Change in the genetic makeup of a population over time is evolution.}

Natural selection is the major driving mechanism of evolution; the essential features of the mechanism contribute to the change in the genetic makeup of a population over time. Darwin's theory of natural selection states that inheritable variations occur in individuals in a population. Due to competition for resources that are often limited, individuals with more favorable variations or phenotypes are more likely to survive and produce more offspring, thus passing traits to subsequent generations. Fitness, the number of surviving offspring left to produce the next generation, is a measure of evolutionary success. Individuals do not evolve, but rather, populations evolve.

The environment is always changing, there is no "perfect" genome, and a diverse gene pool is important for the long-term survival of a species. Genetic variations within a population contribute to the diversity of the gene pool. Changes in genetic information may be silent (with no observable phenotypic effects) or result in a new phenotype, which can be positive, negative or neutral to the organism. The interaction of the environment and the phenotype determines the fitness of the phenotype; thus, the environment does not direct the changes in DNA, but acts upon phenotypes that occur through random changes in DNA. These changes can involve alterations in DNA sequences, changes in gene combinations and/or the formation of new gene combinations.

Although natural selection is usually the major mechanism for evolution, genetic variation in populations can occur through other processes, including mutation, genetic drift, sexual selection and artificial selection. Inbreeding, small population size, nonrandom mating, the absence of migration, and a net lack of mutations can lead to loss of genetic diversity. Human-directed processes such as genetic engineering can also result in new genes and combinations of alleles that confer new phenotypes.

Biological evolution driven by natural selection is supported by evidence from many scientific disciplines, including geology and physical science. In addition, biochemical, morphological, and genetic information from existing and extinct organisms support the concept of natural selection. Phylogenetic trees serve as dynamic models that show common ancestry, while geographical distribution and the fossil record link past and present organisms.

Essential knowledge 1.A.1: Natural selection is a major mechanism of evolution.

a. According to Darwin's theory of natural selection, competition for limited resources results in differential survival. Individuals with more favorable phenotypes are more likely to survive and produce more offspring, thus passing traits to subsequent generations.

b. Evolutionary fitness is measured by reproductive success. 
c. Genetic variation and mutation play roles in natural selection. A diverse gene pool is important for the survival of a species in a changing environment.

d. Environments can be more or less stable or fluctuating, and this affects evolutionary rate and direction; different genetic variations can be selected in each generation.

e. An adaptation is a genetic variation that is favored by selection and is manifested as a trait that provides an advantage to an organism in a particular environment.

f. In addition to natural selection, chance and random events can influence the evolutionary process, especially for small populations.

g. Conditions for a population or an allele to be in Hardy-Weinberg equilibrium are: (1) a large population size, (2) absence of migration, (3) no net mutations, (4) random mating and (5) absence of selection. These conditions are seldom met.

h. Mathematical approaches are used to calculate changes in allele frequency, providing evidence for the occurrence of evolution in a population.

To foster student understanding of this concept, instructors can choose an illustrative example such as:

- Graphical analysis of allele frequencies in a population

- Application of the Hardy-Weinberg equilibrium equation

\section{Learning Objectives:}

LO 1.1 The student is able to convert a data set from a table of numbers that reflect a change in the genetic makeup of a population over time and to apply mathematical methods and conceptual understandings to investigate the cause(s) and effect(s) of this change. [See SP 1.5, 2.2]

LO 1.2 The student is able to evaluate evidence provided by data to qualitatively and quantitatively investigate the role of natural selection in evolution. [See SP 2.2, 5.3]

LO 1.3 The student is able to apply mathematical methods to data from a real or simulated population to predict what will happen to the population in the future. [See SP 2.2]

\section{Essential knowledge 1.A.2: Natural selection acts on phenotypic variations in populations.}

a. Environments change and act as selective mechanism on populations.

To foster student understanding of this concept, instructors can choose an illustrative example such as:

- Flowering time in relation to global climate change

- $\quad$ Peppered moth 
b. Phenotypic variations are not directed by the environment but occur through random changes in the DNA and through new gene combinations.

c. Some phenotypic variations significantly increase or decrease fitness of the organism and the population.

To foster student understanding of this concept, instructors can choose an illustrative example such as:

- Sickle cell anemia

- Peppered moth

- DDT resistance in insects

d. Humans impact variation in other species.

To foster student understanding of this concept, instructors can choose an illustrative example such as:

- Artificial selection

- Loss of genetic diversity within a crop species

- Overuse of antibiotics

Learning Objectives:

LO 1.4 The student is able to evaluate data-based evidence that describes evolutionary changes in the genetic makeup of a population over time. [See SP 5.3]

LO 1.5 The student is able to connect evolutionary changes in a population over time to a change in the environment.[See SP 7.1]

Essential knowledge 1.A.3: Evolutionary change is also driven by random processes.

a. Genetic drift is a nonselective process occurring in small populations.

b. Reduction of genetic variation within a given population can increase the differences between populations of the same species.

Learning Objectives:

LO 1.6 The student is able to use data from mathematical models based on the Hardy-Weinberg equilibrium to analyze genetic drift and effects of selection in the evolution of specific populations. [See SP 1.4, 2.1] 
LO 1.7 The student is able to justify data from mathematical models based on the Hardy-Weinberg equilibrium to analyze genetic drift and the effects of selection in the evolution of specific populations. [See SP 2.1]

LO 1.8 The student is able to make predictions about the effects of genetic drift, migration and artificial selection on the genetic makeup of a population.

[See SP 6.4]

Essential knowledge 1.A.4: Biological evolution is supported by scientific evidence from many disciplines, including mathematics.

a. Scientific evidence of biological evolution uses information from geographical, geological, physical, chemical and mathematical applications.

b. Molecular, morphological and genetic information of existing and extinct organisms add to our understanding of evolution.

Evidence of student learning is a demonstrated understanding of each of the following:

1. Fossils can be dated by a variety of methods that provide evidence for evolution. These include the age of the rocks where a fossil is found, the rate of decay of isotopes including carbon-14, the relationships within phylogenetic trees, and the mathematical calculations that take into account information from chemical properties and/or geographical data.

X The details of these methods are beyond the scope of this course and the AP Exam.

2. Morphological homologies represent features shared by common ancestry. Vestigial structures are remnants of functional structures, which can be compared to fossils and provide evidence for evolution.

3. Biochemical and genetic similarities, in particular DNA nucleotide and protein sequences, provide evidence for evolution and ancestry.

4. Mathematical models and simulations can be used to illustrate and support evolutionary concepts.

To foster student understanding of this concept, instructors can choose an illustrative example such as:

- Graphical analyses of allele frequencies in a population

- Analysis of sequence data sets

- Analysis of phylogenetic trees

- Construction of phylogenetic trees based on sequence data 
Learning Objectives:

LO 1.9 The student is able to evaluate evidence provided by data from many scientific disciplines that support biological evolution. [See SP 5.3]

LO 1.10 The student is able to refine evidence based on data from many scientific disciplines that support biological evolution. [See SP 5.2]

LO 1.11 The student is able to design a plan to answer scientific questions regarding how organisms have changed over time using information from morphology, biochemistry and geology. [See SP 4.2]

LO 1.12 The student is able to connect scientific evidence from many scientific disciplines to support the modern concept of evolution. [See SP 7.1]

LO 1.13 The student is able to construct and/or justify mathematical models, diagrams or simulations that represent processes of biological evolution. [See SP 1.1, 2.1]

\section{Enduring understanding 1.B: Organisms are linked by lines of descent from common ancestry.}

Organisms share many conserved core processes and features that are widely distributed among organisms today. These processes provide evidence that all organisms (Archaea, Bacteria, and Eukarya, both extant and extinct) are linked by lines of descent from common ancestry. Elements that are conserved across all domains of life are DNA and RNA as carriers of genetic information, a universal genetic code, and many metabolic pathways. The existence of these properties in organisms today implies that they were present in a universal ancestor and that present life evolved from a universal ancestor. Phylogenetic trees graphically model evolutionary history and can represent both acquired traits and those lost during evolution.

In eukaryotes, conserved core elements provide evidence for evolution. These features include the presence of a cytoskeleton, a nucleus, membrane-bound organelles, linear chromosomes and endomembrane systems.

Essential knowledge 1.B.1: Organisms share many conserved core processes and features that evolved and are widely distributed among organisms today.

a. Structural and functional evidence supports the relatedness of all domains. Evidence of student learning is a demonstrated understanding of each of the following:

1. DNA and RNA are carriers of genetic information through transcription, translation and replication. [See also 3.A.1 ]

2. Major features of the genetic code are shared by all modern living systems. [See also 3.A.1]. 
3. Metabolic pathways are conserved across all currently recognized domains. [See also 3.D.1].

b. Structural evidence supports the relatedness of all eukaryotes. [See also 2.B.3, 4.A.2] To foster student understanding of this concept, instructors can choose an illustrative example such as:

- Cytoskeleton (a network of structural proteins that facilitate cell movement, morphological integrity and organelle transport)

- Membrane-bound organelles (mitochondria and/or chloroplasts)

- Linear chromosomes

- Endomembrane systems, including the nuclear envelope

Learning Objectives:

LO 1.14 The student is able to pose scientific questions that correctly identify essential properties of shared, core life processes that provide insights into the history of life on Earth. [See SP 3.1]

LO 1.15 The student is able to describe specific examples of conserved core biological processes and features shared by all domains or within one domain of life, and how these shared, conserved core processes and features support the concept of common ancestry for all organisms. [See SP 7.2]

LO 1.16 The student is able to justify the scientific claim that organisms share many conserved core processes and features that evolved and are widely distributed among organisms today. [See SP 6.1]

Essential knowledge 1.B.2: Phylogenetic trees and cladograms are graphical representations (models) of evolutionary history that can be tested.

a. Phylogenetic trees and cladograms can represent traits that are either derived or lost due to evolution.

To foster student understanding of this concept, instructors can choose an illustrative example such as:

- Number of heart chambers in animals

- Opposable thumbs

- Absence of legs in some sea mammals

b. Phylogenetic trees and cladograms illustrate speciation that has occurred, in that relatedness of any two groups on the tree is shown by how recently two groups had a common ancestor. 
c. Phylogenetic trees and cladograms can be constructed from morphological similarities of living or fossil species, and from DNA and protein sequence similarities, by employing computer programs that have sophisticated ways of measuring and representing relatedness among organisms.

d. Phylogenetic trees and cladograms are dynamic (i.e., phylogenetic trees and cladograms are constantly being revised), based on the biological data used, new mathematical and computational ideas, and current and emerging knowledge.

Learning Objectives:

LO 1.17 The student is able to pose scientific questions about a group of organisms whose relatedness is described by a phylogenetic tree or cladogram in order to (1) identify shared characteristics, (2) make inferences about the evolutionary history of the group, and (3) identify character data that could extend or improve the phylogenetic tree. [See SP 3.1]

LO 1.18 The student is able to evaluate evidence provided by a data set in conjunction with a phylogenetic tree or a simple cladogram to determine evolutionary history and speciation. [See SP 5.3]

LO 1.19 The student is able create a phylogenetic tree or simple cladogram that correctly represents evolutionary history and speciation from a provided data set. [See SP 1.1]

\section{Enduring understanding 1.C: Life continues to evolve within a changing environment.}

Speciation and extinction have occurred throughout the Earth's history, and life continues to evolve within a changing environment. However, the rates of speciation and extinction vary. Speciation can be slow and gradual or, as described by punctuated equilibrium, can occur in "bursts" followed by relatively quiet periods. At times of ecological stress, extinction rates can be rapid, and mass extinctions are often followed by adaptive radiation, the rapid evolution of species when new habitats open. Scientific evidence, including emergent diseases, chemical resistance and genomic data, supports the idea that evolution occurs for all organisms and that evolution explains the diversity of life on the planet.

A species can be defined as a group of individuals capable of interbreeding and exchanging genetic information to produce viable, fertile offspring. New species arise when two populations diverge from a common ancestor and become reproductively isolated. Although speciation can occur by different processes, reproductive isolation must be maintained for a species to remain distinct. Evidence that speciation has occurred includes fossil records and genomic data. 


\section{Essential knowledge 1.C.1: Speciation and extinction have occurred} throughout the Earth's history.

a. Speciation rates can vary, especially when adaptive radiation occurs when new habitats become available.

b. Species extinction rates are rapid at times of ecological stress. [See also 4.C.3] To foster student understanding of this concept, instructors can choose an illustrative example such as:

- Five major extinctions

- Human impact on ecosystems and species extinction rates

$\mathbf{X}$ The names and dates of these extinctions are beyond the scope of this course and the AP Exam.

Learning Objectives:

LO 1.20 The student is able to analyze data related to questions of speciation and extinction throughout the Earth's history. [See SP 5.1]

LO 1.21 The student is able to design a plan for collecting data to investigate the scientific claim that speciation and extinction have occurred throughout the Earth's history. [See SP 4.2]

Essential knowledge 1.C.2: Speciation may occur when two populations become reproductively isolated from each other.

a. Speciation results in diversity of life forms. Species can be physically separated by a geographic barrier such as an ocean or a mountain range, or various pre-and post-zygotic mechanisms can maintain reproductive isolation and prevent gene flow.

b. New species arise from reproductive isolation over time, which can involve scales of hundreds of thousands or even millions of years, or speciation can occur rapidly through mechanisms such as polyploidy in plants.

Learning Objectives:

LO 1.22 The student is able to use data from a real or simulated population(s), based on graphs or models of types of selection, to predict what will happen to the population in the future. [See SP 6.4]

LO 1.23 The student is able to justify the selection of data that address questions related to reproductive isolation and speciation. [See SP 4.1] 
LO 1.24 The student is able to describe speciation in an isolated population and connect it to change in gene frequency, change in environment, natural selection and/or genetic drift. [See SP 7.2]

\section{Essential knowledge 1.C.3: Populations of organisms continue to evolve.}

a. Scientific evidence supports the idea that evolution has occurred in all species.

b. Scientific evidence supports the idea that evolution continues to occur.

To foster student understanding of this concept, instructors can choose an illustrative example such as:

- Chemical resistance (mutations for resistance to antibiotics, pesticides, herbicides or chemotherapy drugs occur in the absence of the chemical)

- Emergent diseases

- Observed directional phenotypic change in a population (Grants' observations of Darwin's finches in the Galapagos)

- A eukaryotic example that describes evolution of a structure or process such as heart chambers, limbs, the brain and the immune system

Learning Objectives:

LO 1.25 The student is able to describe a model that represents evolution within a population. [See SP 1.2]

LO 1.26 The student is able to evaluate given data sets that illustrate evolution as an ongoing process. [See SP 5.3]

\section{Enduring understanding 1.D: The origin of living systems is explained by natural processes.}

The process of evolution explains the diversity and unity of life. A number of experimental investigations have provided evidence that the conditions early in the Earth's history provided an environment capable of generating complex organic molecules and simple cell-like structures. For example, in the "organic soup" model, the hypothesized primitive atmosphere contained inorganic precursors from which organic molecules could have been synthesized through natural chemical reactions catalyzed by the input of energy. In turn, these molecules served as monomers (building blocks) for the formation of more complex molecules, including amino acids and nucleotides. Some models suggest that primitive life developed on biogenic surfaces, such as clay, that served as templates and catalysts for assembly of macromolecules. Under laboratory conditions, complex polymers and self-replicating 
molecules can spontaneously assemble. It remains an open question whether the first genetic and self-replicating material was DNA or RNA.

Essential knowledge 1.D.1: There are several hypotheses about the natural origin of life on Earth, each with supporting scientific evidence.

a. Scientific evidence supports the various models.

Evidence of student learning is a demonstrated understanding of each of the following:

1. Primitive Earth provided inorganic precursors from which organic molecules could have been synthesized due to the presence of available free energy and the absence of a significant quantity of oxygen.

2. In turn, these molecules served as monomers or building blocks for the formation of more complex molecules, including amino acids and nucleotides. [See also 4.A.1]

3. The joining of these monomers produced polymers with the ability to replicate, store and transfer information.

4. These complex reaction sets could have occurred in solution (organic soup model) or as reactions on solid reactive surfaces. [See also 2.B.1]

5. The RNA World hypothesis proposes that RNA could have been the earliest genetic material.

Learning Objectives:

LO 1.27 The student is able to describe a scientific hypothesis about the origin of life on Earth. [See SP 1.2]

LO 1.28 The student is able to evaluate scientific questions based on hypotheses about the origin of life on Earth. [See SP 3.3]

LO 1.29 The student is able to describe the reasons for revisions of scientific hypotheses of the origin of life on Earth. [See SP 6.3]

LO 1.30 The student is able to evaluate scientific hypotheses about the origin of life on Earth. [See SP 6.5]

LO 1.31 The student is able to evaluate the accuracy and legitimacy of data to answer scientific questions about the origin of life on Earth. [See SP 4.4]

\section{Essential knowledge 1.D.2: Scientific evidence from many different} disciplines supports models of the origin of life.

a. Geological evidence provides support for models of the origin of life on Earth. 
Evidence of student learning is a demonstrated understanding of each of the following:

1. The Earth formed approximately 4.6 billion years ago (bya), and the environment was too hostile for life until 3.9 bya, while the earliest fossil evidence for life dates to 3.5 bya. Taken together, this evidence provides a plausible range of dates when the origin of life could have occurred.

2. Chemical experiments have shown that it is possible to form complex organic molecules from inorganic molecules in the absence of life.

b. Molecular and genetic evidence from extant and extinct organisms indicates that all organisms on Earth share a common ancestral origin of life.

Evidence of student learning is a demonstrated understanding of each of the following:

1. Scientific evidence includes molecular building blocks that are common to all life forms.

2. Scientific evidence includes a common genetic code.

\section{Learning Objective:}

LO 1.32 The student is able to justify the selection of geological, physical, and chemical data that reveal early Earth conditions. [See SP 4.1]

\section{Big Idea 2: Biological systems utilize free energy and molecular building blocks to grow, to reproduce and to maintain dynamic homeostasis.}

Living systems require free energy and matter to maintain order, grow and reproduce. Organisms employ various strategies to capture, use and store free energy and other vital resources. Energy deficiencies are not only detrimental to individual organisms; they also can cause disruptions at the population and ecosystem levels.

Autotrophic cells capture free energy through photosynthesis and chemosynthesis. Photosynthesis traps free energy present in sunlight that, in turn, is used to produce carbohydrates from carbon dioxide. Chemosynthesis captures energy present in inorganic chemicals. Cellular respiration and fermentation harvest free energy from sugars to produce free energy carriers, including ATP. The free energy available in sugars drives metabolic pathways in cells. Photosynthesis and respiration are interdependent processes.

Cells and organisms must exchange matter with the environment. For example, water and nutrients are used in the synthesis of new molecules; carbon moves from the environment to organisms where it is incorporated into carbohydrates, proteins, nucleic acids or fats; and oxygen is necessary for more efficient free energy use in cellular respiration. Differences in surface-to-volume ratios affect the capacity of a biological system to obtain 
resources and eliminate wastes. Programmed cell death (apoptosis) plays a role in normal development and differentiation (e.g. morphogenesis).

Membranes allow cells to create and maintain internal environments that differ from external environments. The structure of cell membranes results in selective permeability; the movement of molecules across them via osmosis, diffusion and active transport maintains dynamic homeostasis. In eukaryotes, internal membranes partition the cell into specialized regions that allow cell processes to operate with optimal efficiency. Each compartment or membrane-bound organelle enables localization of chemical reactions.

Organisms also have feedback mechanisms that maintain dynamic homeostasis by allowing them to respond to changes in their internal and external environments. Negative feedback loops maintain optimal internal environments, and positive feedback mechanisms amplify responses. Changes in a biological system's environment, particularly the availability of resources, influence responses and activities, and organisms use various means to obtain nutrients and get rid of wastes. Homeostatic mechanisms across phyla reflect both continuity due to common ancestry and change due to evolution and natural selection; in plants and animals, defense mechanisms against disruptions of dynamic homeostasis have evolved. Additionally, the timing and coordination of developmental, physiological and behavioral events are regulated, increasing fitness of individuals and long-term survival of populations.

\section{Enduring understanding 2.A: Growth, reproduction and maintenance of the organization of living systems require free energy and matter.}

Living systems require energy to maintain order, grow and reproduce. In accordance with the laws of thermodynamics, to offset entropy, energy input must exceed energy lost from and used by an organism to maintain order. Organisms use various energy-related strategies to survive; strategies include different metabolic rates, physiological changes, and variations in reproductive and offspring-raising strategies. Not only can energy deficiencies be detrimental to individual organisms, but changes in free energy availability also can affect population size and cause disruptions at the ecosystem level.

Several means to capture, use and store free energy have evolved in organisms. Cells can capture free energy through photosynthesis and chemosynthesis. Autotrophs capture free energy from the environment, including energy present in sunlight and chemical sources, whereas heterotrophs harvest free energy from carbon compounds produced by other organisms. Through a series of coordinated reaction pathways, photosynthesis traps free energy in sunlight that, in turn, is used to produce carbohydrates from carbon dioxide and water. Cellular respiration and fermentation use free energy available from sugars and from interconnected, multistep pathways (i.e., glycolysis, the Krebs cycle and the electron transport chain) to phosphorylate ADP, producing the most common energy carrier, ATP. The free energy available in sugars can be used to drive metabolic pathways vital to cell processes. The processes of photosynthesis and cellular respiration are interdependent in their reactants and products. 
Organisms must exchange matter with the environment to grow, reproduce and maintain organization. The cellular surface-to-volume ratio affects a biological system's ability to obtain resources and eliminate waste products. Water and nutrients are essential for building new molecules. Carbon dioxide moves from the environment to photosynthetic organisms where it is metabolized and incorporated into carbohydrates, proteins, nucleic acids or lipids. Nitrogen is essential for building nucleic acids and proteins; phosphorus is incorporated into nucleic acids, phospholipids, ATP and ADP. In aerobic organisms, oxygen serves as an electron acceptor in energy transformations.

Essential knowledge 2.A.1: All living systems require constant input of free energy.

a. Life requires a highly ordered system.

Evidence of student learning is a demonstrated understanding of each of the following:

1. Order is maintained by constant free energy input into the system.

2. Loss of order or free energy flow results in death.

3. Increased disorder and entropy are offset by biological processes that maintain or increase order.

b. Living systems do not violate the second law of thermodynamics, which states that entropy increases over time.

Evidence of student learning is a demonstrated understanding of each of the following:

1. Order is maintained by coupling cellular processes that increase entropy (and so have negative changes in free energy) with those that decrease entropy (and so have positive changes in free energy).

2. Energy input must exceed free energy lost to entropy to maintain order and power cellular processes.

3. Energetically favorable exergonic reactions, such as ATP $\rightarrow$ ADP, that have a negative change in free energy can be used to maintain or increase order in a system by being coupled with reactions that have a positive free energy change.

c. Energy-related pathways in biological systems are sequential and may be entered at multiple points in the pathway. [See also 2.A.2]

To foster student understanding of this concept, instructors can choose an illustrative example such as:

- Krebs cycle

- Glycolysis

- Calvin cycle

- Fermentation 
d. Organisms use free energy to maintain organization, grow and reproduce.

Evidence of student learning is a demonstrated understanding of each of the following:

1. Organisms use various strategies to regulate body temperature and metabolism. To foster student understanding of this concept, instructors can choose an illustrative example such as:

- Endothermy (the use of thermal energy generated by metabolism to maintain homeostatic body temperatures)

- Ectothermy (the use of external thermal energy to help regulate and maintain body temperature)

- Elevated floral temperatures in some plant species

2. Reproduction and rearing of offspring require free energy beyond that used for maintenance and growth. Different organisms use various reproductive strategies in response to energy availability.

To foster student understanding of this concept, instructors can choose an illustrative example such as:

- Seasonal reproduction in animals and plants

- Life-history strategy (biennial plants, reproductive diapause)

3. There is a relationship between metabolic rate per unit body mass and the size of multicellular organisms - generally, the smaller the organism, the higher the metabolic rate.

4. Excess acquired free energy versus required free energy expenditure results in energy storage or growth.

5. Insufficient acquired free energy versus required free energy expenditure results in loss of mass and, ultimately, the death of an organism.

e. Changes in free energy availability can result in changes in population size.

f. Changes in free energy availability can result in disruptions to an ecosystem.

To foster student understanding of this concept, instructors can choose an illustrative example such as:

- Change in the producer level can affect the number and size of other trophic levels.

- Change in energy resources levels such as sunlight can affect the number and size of the trophic levels. 
Learning Objectives:

LO 2.1 The student is able to explain how biological systems use free energy based on empirical data that all organisms require constant energy input to maintain organization, to grow and to reproduce. [See SP 6.2]

LO 2.2 The student is able to justify a scientific claim that free energy is required for living systems to maintain organization, to grow or to reproduce, but that multiple strategies exist in different living systems. [See SP 6.1]

LO 2.3 The student is able to predict how changes in free energy availability affect organisms, populations and ecosystems. [See SP 6.4]

Essential knowledge 2.A.2: Organisms capture and store free energy for use in biological processes.

a. Autotrophs capture free energy from physical sources in the environment. Evidence of student learning is a demonstrated understanding of each of the following:

1. Photosynthetic organisms capture free energy present in sunlight.

2. Chemosynthetic organisms capture free energy from small inorganic molecules present in their environment, and this process can occur in the absence of oxygen.

b. Heterotrophs capture free energy present in carbon compounds produced by other organisms.

Evidence of student learning is a demonstrated understanding of each of the following:

1. Heterotrophs may metabolize carbohydrates, lipids and proteins by hydrolysis as sources of free energy.

2. Fermentation produces organic molecules, including alcohol and lactic acid, and it occurs in the absence of oxygen.

X Specific steps, names of enzymes and intermediates of the pathways for these processes are beyond the scope of the course and the AP Exam.

c. Different energy-capturing processes use different types of electron acceptors.

To foster student understanding of this concept, instructors can choose an illustrative example such as:

- $\mathrm{NADP}^{+}$in photosynthesis

- Oxygen in cellular respiration

d. The light-dependent reactions of photosynthesis in eukaryotes involve a series of coordinated reaction pathways that capture free energy present in light to yield ATP and NADPH, which power the production of organic molecules. 
Evidence of student learning is a demonstrated understanding of each of the following:

1. During photosynthesis, chlorophylls absorb free energy from light, boosting electrons to a higher energy level in Photosystems I and II.

2. Photosystems I and II are embedded in the internal membranes of chloroplasts (thylakoids) and are connected by the transfer of higher free energy electrons through an electron transport chain (ETC). [See also 4.A.2]

3. When electrons are transferred between molecules in a sequence of reactions as they pass through the ETC, an electrochemical gradient of hydrogen ions (protons) across the thykaloid membrane is established.

4. The formation of the proton gradient is a separate process, but it is linked to the synthesis of ATP from ADP and inorganic phosphate via ATP synthase.

5. The energy captured in the light reactions as ATP and NADPH powers the production of carbohydrates from carbon dioxide in the Calvin cycle, which occurs in the stroma of the chloroplast.

X Memorization of the steps in the Calvin cycle, the structure of the molecules and the names of enzymes (with the exception of ATP synthase) are beyond the scope of the course and the AP Exam.

e. Photosynthesis first evolved in prokaryotic organisms; scientific evidence supports that prokaryotic (bacterial) photosynthesis was responsible for the production of an oxygenated atmosphere; prokaryotic photosynthetic pathways were the foundation of eukaryotic photosynthesis.

f. Cellular respiration in eukaryotes involves a series of coordinated enzymecatalyzed reactions that harvest free energy from simple carbohydrates.

Evidence of student learning is a demonstrated understanding of each of the following:

1. Glycolysis rearranges the bonds in glucose molecules, releasing free energy to form ATP from ADP and inorganic phosphate, and resulting in the production of pyruvate.

2. Pyruvate is transported from the cytoplasm to the mitochondrion, where further oxidation occurs. [See also 4.A.2]

3. In the Krebs cycle, carbon dioxide is released from organic intermediates ATP is synthesized from ADP and inorganic phosphate via substrate level phosphorylation and electrons are captured by coenzymes.

4. Electrons that are extracted in the series of Krebs cycle reactions are carried by $\mathrm{NADH}$ and FADH2 to the electron transport chain.

X Memorization of the steps in glycolysis and the Krebs cycle, or of the structures of the molecules and the names of the enzymes involved, are beyond the scope of the course and the AP Exam. 
g. The electron transport chain captures free energy from electrons in a series of coupled reactions that establish an electrochemical gradient across membranes.

Evidence of student learning is a demonstrated understanding of each of the following:

1. Electron transport chain reactions occur in chloroplasts (photosynthesis), mitochondria (cellular respiration) and prokaryotic plasma membranes.

2. In cellular respiration, electrons delivered by $\mathrm{NADH}$ and FADH2 are passed to a series of electron acceptors as they move toward the terminal electron acceptor, oxygen. In photosynthesis, the terminal electron acceptor is NADP+.

3. The passage of electrons is accompanied by the formation of a proton gradient across the inner mitochondrial membrane or the thylakoid membrane of chloroplasts, with the membrane(s) separating a region of high proton concentration from a region of low proton concentration. In prokaryotes, the passage of electrons is accompanied by the outward movement of protons across the plasma membrane.

4. The flow of protons back through membrane-bound ATP synthase by chemiosmosis generates ATP from ADP and inorganic phosphate.

5. In cellular respiration, decoupling oxidative phosphorylation from electron transport is involved in thermoregulation.

$\mathbf{X}$ The names of the specific electron carriers in the ETC are beyond the scope of the course and the AP Exam.

h. Free energy becomes available for metabolism by the conversion of ATP $\rightarrow$ ADP, which is coupled to many steps in metabolic pathways.

Learning Objectives:

LO 2.4 The student is able to use representations to pose scientific questions about what mechanisms and structural features allow organisms to capture, store and use free energy. [See SP 1.4, 3.1]

LO 2.5 The student is able to construct explanations of the mechanisms and structural features of cells that allow organisms to capture, store or use free energy. [See SP 6.2]

\section{Essential knowledge 2.A.3: Organisms must exchange matter with the environment to grow, reproduce and maintain organization.}

a. Molecules and atoms from the environment are necessary to build new molecules. Evidence of student learning is a demonstrated understanding of each of the following:

1. Carbon moves from the environment to organisms where it is used to build 
carbohydrates, proteins, lipids or nucleic acids. Carbon is used in storage compounds and cell formation in all organisms.

2. Nitrogen moves from the environment to organisms where it is used in building proteins and nucleic acids. Phosphorus moves from the environment to organisms where it is used in nucleic acids and certain lipids.

3. Living systems depend on properties of water that result from its polarity and hydrogen bonding.

To foster student understanding of this concept, instructors can choose an illustrative example such as:

- Cohesion

- Adhesion

- High specific heat capacity

- Universal solvent supports reactions

- Heat of vaporization

- Heat of fusion

- Water's thermal conductivity

b. Surface area-to-volume ratios affect a biological system's ability to obtain necessary resources or eliminate waste products.

Evidence of student learning is a demonstrated understanding of each of the following:

1. As cells increase in volume, the relative surface area decreases and demand for material resources increases; more cellular structures are necessary to adequately exchange materials and energy with the environment. These limitations restrict cell size.

To foster student understanding of this concept, instructors can choose an illustrative example such as:

- Root hairs

- Cells of the alveoli

- Cells of the villi

- Microvilli

2. The surface area of the plasma membrane must be large enough to adequately exchange materials; smaller cells have a more favorable surface area-to-volume ratio for exchange of materials with the environment.

Learning Objectives:

LO 2.6 The student is able to use calculated surface area-to-volume ratios to predict which cell(s) might eliminate wastes or procure nutrients faster by diffusion.

[See SP 2.2] 
LO 2.7 Students will be able to explain how cell size and shape affect the overall rate of nutrient intake and the rate of waste elimination. [See SP 6.2]

LO 2.8 The student is able to justify the selection of data regarding the types of molecules that an animal, plant or bacterium will take up as necessary building blocks and excrete as waste products. [See SP 4.1]

LO 2.9 The student is able to represent graphically or model quantitatively the exchange of molecules between an organism and its environment, and the subsequent use of these molecules to build new molecules that facilitate dynamic homeostasis, growth and reproduction. [See SP 1.1, 1.4]

\section{Enduring understanding 2.B: Growth, reproduction and dynamic homeostasis require that cells create and maintain internal environments that are different from their external environments.}

Cell membranes separate the internal environment of the cell from the external environment. The specialized structure of the membrane described in the fluid mosaic model allows the cell to be selectively permeable, with dynamic homeostasis maintained by the constant movement of molecules across the membrane. Passive transport does not require the input of metabolic energy because spontaneous movement of molecules occurs from high to low concentrations; examples of passive transport are osmosis, diffusion, and facilitated diffusion. Active transport requires metabolic energy and transport proteins to move molecules from low to high concentrations across a membrane. Active transport establishes concentration gradients vital for dynamic homeostasis, including sodium/potassium pumps in nerve impulse conduction and proton gradients in electron transport chains in photosynthesis and cellular respiration. The processes of endocytosis and exocytosis move large molecules from the external environment to the internal environment and vice versa, respectively.

Eukaryotic cells also maintain internal membranes that partition the cell into specialized regions so that cell processes can operate with optimal efficiency by increasing beneficial interactions, decreasing conflicting interactions and increasing surface area for chemical reactions to occur. Each compartment or membrane-bound organelle localizes reactions, including energy transformation in mitochondria and production of proteins in rough endoplasmic reticulum.

Essential knowledge 2.B.1: Cell membranes are selectively permeable due to their structure.

a. Cell membranes separate the internal environment of the cell from the external environment.

b. Selective permeability is a direct consequence of membrane structure, as described by the fluid mosaic model. [See also 4.A.1] 
Evidence of student learning is a demonstrated understanding of each of the following:

1. Cell membranes consist of a structural framework of phospholipid molecules, embedded proteins, cholesterol, glycoproteins and glycolipids.

2. Phospholipids give the membrane both hydrophilic and hydrophobic properties. The hydrophilic phosphate portions of the phospholipids are oriented toward the aqueous external or internal environments, while the hydrophobic fatty acid portions face each other within the interior of the membrane itself.

3. Embedded proteins can be hydrophilic, with charged and polar side groups, or hydrophobic, with nonpolar side groups.

4. Small, uncharged polar molecules and small nonpolar molecules, such as $\mathrm{N}_{2}$, freely pass across the membrane. Hydrophilic substances such as large polar molecules and ions move across the membrane through embedded channel and transport proteins. Water moves across membranes and through channel proteins called aquaporins.

c. Cell walls provide a structural boundary, as well as a permeability barrier for some substances to the internal environments.

Evidence of student learning is a demonstrated understanding of each of the following:

1. Plant cell walls are made of cellulose and are external to the cell membrane.

2. Other examples are cells walls of prokaryotes and fungi.

Learning Objectives:

LO 2.10 The student is able to use representations and models to pose scientific questions about the properties of cell membranes and selective permeability based on molecular structure. [See SP 1.4, 3.1]

LO 2.11 The student is able to construct models that connect the movement of molecules across membranes with membrane structure and function.

[See SP 1.1, 7.1, 7.2]

Essential knowledge 2.B.2: Growth and dynamic homeostasis are maintained by the constant movement of molecules across membranes.

a. Passive transport does not require the input of metabolic energy; the net movement of molecules is from high concentration to low concentration.

Evidence of student learning is a demonstrated understanding of each of the following:

1. Passive transport plays a primary role in the import of resources and the export of wastes.

2. Membrane proteins play a role in facilitated diffusion of charged and polar molecules through a membrane. 
To foster student understanding of this concept, instructors can choose an illustrative example such as:

- Glucose transport

- $\mathrm{Na}^{+} / \mathrm{K}^{+}$transport

$\mathbf{X}$ There is no particular membrane protein that is required for teaching this concept.

3. External environments can be hypotonic, hypertonic or isotonic to internal environments of cells.

b. Active transport requires free energy to move molecules from regions of low concentration to regions of high concentration.

Evidence of student learning is a demonstrated understanding of each of the following:

1. Active transport is a process where free energy (often provided by ATP) is used by proteins embedded in the membrane to "move" molecules and/or ions across the membrane and to establish and maintain concentration gradients.

2. Membrane proteins are necessary for active transport.

c. The processes of endocytosis and exocytosis move large molecules from the external environment to the internal environment and vice versa, respectively. Evidence of student learning is a demonstrated understanding of each of the following:

1. In exocytosis, internal vesicles fuse with the plasma membrane to secrete large macromolecules out of the cell.

2. In endocytosis, the cell takes in macromolecules and particulate matter by forming new vesicles derived from the plasma membrane.

\section{Learning Objective:}

LO 2.12 The student is able to use representations and models to analyze situations or solve problems qualitatively and quantitatively to investigate whether dynamic homeostasis is maintained by the active movement of molecules across membranes. [See SP 1.4]

\section{Essential knowledge 2.B.3: Eukaryotic cells maintain internal} membranes that partition the cell into specialized regions.

a. Internal membranes facilitate cellular processes by minimizing competing interactions and by increasing surface area where reactions can occur.

b. Membranes and membrane-bound organelles in eukaryotic cells localize (compartmentalize) intracellular metabolic processes and specific enzymatic reactions. [See also 4.A.2] 
To foster student understanding of this concept, instructors can choose an illustrative example, such as:

- Endoplasmic reticulum

- Mitochondria

- Chloroplasts

- Golgi

- Nuclear envelope

c. Archaea and Bacteria generally lack internal membranes and organelles and have a cell wall.

Learning Objectives:

LO 2.13 The student is able to explain how internal membranes and organelles contribute to cell functions. [See SP 6.2]

LO 2.14 The student is able to use representations and models to describe differences in prokaryotic and eukaryotic cells. [See SP 1.4]

\section{Enduring understanding 2.C: Organisms use feedback mechanisms to regulate growth and reproduction, and to maintain dynamic homeostasis.}

Organisms respond to changes in their internal and external environments through behavioral and physiological mechanisms, such as photoperiodism in plants, hibernation and migration in animals, and shivering and sweating in humans. Organisms use negative feedback mechanisms to maintain their internal environments by returning the changing condition back to its target set point, while positive feedback mechanisms amplify responses. Examples of negative feedback responses include temperature regulation in animals and plant responses to drought; examples of positive feedback mechanisms are the onset of labor in childbirth and ripening of fruit. Alterations in feedback mechanisms can have deleterious effects, including diabetes and Graves' disease in humans and the inability of plants to tolerate water stress during drought.

\section{Essential knowledge 2.C.1: Organisms use feedback mechanisms to maintain their internal environments and respond to external environmental changes.}

a. Negative feedback mechanisms maintain dynamic homeostasis for a particular condition (variable) by regulating physiological processes, returning the changing condition back to its target set point. 
To foster student understanding of this concept, instructors can choose an illustrative example such as:

- Operons in gene regulation

- Temperature regulation in animals

- Plant responses to water limitations

b. Positive feedback mechanisms amplify responses and processes in biological organisms. The variable initiating the response is moved farther away from the initial set-point. Amplification occurs when the stimulus is further activated which, in turn, initiates an additional response that produces system change.

Students should be able to demonstrate understanding of the above concept by using an illustrative example such as:

- Lactation in mammals

- Onset of labor in childbirth

- Ripening of fruit

c. Alteration in the mechanisms of feedback often results in deleterious consequences.

To foster student understanding of this concept, instructors can choose an illustrative example such as:

- Diabetes mellitus in response to decreased insulin

- Dehydration in response to decreased antidiuretic hormone (ADH)

- Graves' disease (hyperthyroidism)

- Blood clotting

Learning Objectives:

LO 2.15 The student can justify a claim made about the effect(s) on a biological system at the molecular, physiological or organismal level when given a scenario in which one or more components within a negative regulatory system is altered. [See SP 6.1]

LO 2.16 The student is able to connect how organisms use negative feedback to maintain their internal environments. [See SP 7.2]

LO 2.17 The student is able to evaluate data that show the effect(s) of changes in concentrations of key molecules on negative feedback mechanisms. [See SP 5.3]

LO 2.18 The student can make predictions about how organisms use negative feedback mechanisms to maintain their internal environments. [See SP 6.4] 
LO 2.19 The student is able to make predictions about how positive feedback mechanisms amplify activities and processes in organisms based on scientific theories and models. [See SP 6.4]

LO 2.20 The student is able to justify that positive feedback mechanisms amplify responses in organisms. [See SP 6.1]

\section{Essential knowledge 2.C.2: Organisms respond to changes in their external environments.}

a. Organisms respond to changes in their environment through behavioral and physiological mechanisms.

To foster student understanding of this concept, instructors can choose an illustrative example such as:

- Photoperiodism and phototropism in plants

- Hibernation and migration in animals

- Taxis and kinesis in animals

- Chemotaxis in bacteria, sexual reproduction in fungi

- Nocturnal and diurnal activity: circadian rhythms

- Shivering and sweating in humans

X No specific behavioral or physiological mechanism is required for teaching the above concept. Teachers are free to choose the mechanism that best fosters student understanding.

\section{Learning Objective:}

LO 2.21 The student is able to justify the selection of the kind of data needed to answer scientific questions about the relevant mechanism that organisms use to respond to changes in their external environment. [See SP 4.1]

\section{Enduring understanding 2.D: Growth and dynamic homeostasis of a biological system are influenced by changes in the system's environment.}

All biological systems, from cells to ecosystems, are influenced by complex biotic and abiotic interactions. The availability of resources influences activities in cells and organisms; examples include responses to cell density, biofilm(s) formation, temperature responses, and responses to nutrient and water availability. The availability of resources affects a population's stability in size and its genetic composition; examples include birth rates versus death rates from bacteria to mammals and global distribution of food for humans. 
Homeostatic mechanisms reflect both continuity due to common ancestry and change due to evolution in different environments. Supporting evidence includes a sampling of homeostatic control systems that are conserved across biological domains. Organisms have evolved various mechanisms for obtaining nutrients and getting rid of wastes, including gas exchange, osmoregulation and nitrogenous waste production. Disturbances to dynamic homeostasis effect biological processes, and plants and animals have evolved a variety of defenses against infections and other disruptions to homeostasis including immune responses. At the ecosystem level, disruptions impact the balance of the ecosystem and the interactions between specific organisms therein.

Essential knowledge 2.D.1: All biological systems from cells and organisms to populations, communities and ecosystems are affected by complex biotic and abiotic interactions involving exchange of matter and free energy.

a. Cell activities are affected by interactions with biotic and abiotic factors.

To foster student understanding of this concept, instructors can choose an illustrative example such as:

- Cell density

- Biofilms

- Temperature

- Water availability

- Sunlight

b. Organism activities are affected by interactions with biotic and abiotic factors. [See also 4.A.6]

To foster student understanding of this concept, instructors can choose an illustrative example such as:

- Symbiosis (mutualism, commensalism, parasitism)

- Predator-prey relationships

- Water and nutrient availability, temperature, salinity, $\mathrm{pH}$

c. The stability of populations, communities and ecosystems is affected by interactions with biotic and abiotic factors. [See also 4.A.5, 4.A.6]

To foster student understanding of this concept, instructors can choose an illustrative example such as:

- Water and nutrient availability

- Availability of nesting materials and sites

- Food chains and food webs

- Species diversity 
- Population density

- Algal blooms

X No specific example is required for teaching the above concepts. Teachers are free to choose an example that best fosters student understanding.

Learning Objectives:

LO 2.22 The student is able to refine scientific models and questions about the effect of complex biotic and abiotic interactions on all biological systems, from cells and organisms to populations, communities and ecosystems. [See SP 1.3, 3.2]

LO 2.23 The student is able to design a plan for collecting data to show that all biological systems (cells, organisms, populations, communities and ecosystems) are affected by complex biotic and abiotic interactions. [See SP 4.2, 7.2]

LO 2.24 The student is able to analyze data to identify possible patterns and relationships between a biotic or abiotic factor and a biological system (cells, organisms, populations, communities or ecosystems). [See SP 5.1]

Essential knowledge 2.D.2: Homeostatic mechanisms reflect both common ancestry and divergence due to adaptation in different environments.

a. Continuity of homeostatic mechanisms reflects common ancestry, while changes may occur in response to different environmental conditions. [See also 1.B.1]

b. Organisms have various mechanisms for obtaining nutrients and eliminating wastes. To foster student understanding of this concept, instructors can choose an illustrative example such as:

- Gas exchange in aquatic and terrestrial plants

- Digestive mechanisms in animals such as food vacuoles, gastrovascular cavities, one-way digestive systems

- Respiratory systems of aquatic and terrestrial animals

- Nitrogenous waste production and elimination in aquatic and terrestrial animals

c. Homeostatic control systems in species of microbes, plants and animals support common ancestry. [See also 1.B.1]

To foster student understanding of this concept, instructors can choose an illustrative example such as the comparison of:

- Excretory systems in flatworms, earthworms and vertebrates

- Osmoregulation in bacteria, fish and protists

- Osmoregulation in aquatic and terrestrial plants 
- Circulatory systems in fish, amphibians and mammals

- Thermoregulation in aquatic and terrestrial animals (countercurrent exchange mechanisms)

\section{Learning Objectives:}

LO 2.25 The student can construct explanations based on scientific evidence that homeostatic mechanisms reflect continuity due to common ancestry and/or divergence due to adaptation in different environments. [See SP 6.2]

LO 2.26 The student is able to analyze data to identify phylogenetic patterns or relationships, showing that homeostatic mechanisms reflect both continuity due to common ancestry and change due to evolution in different environments. [See SP 5.1]

LO 2.27 The student is able to connect differences in the environment with the evolution of homeostatic mechanisms. [See SP 7.1]

\section{Essential knowledge 2.D.3: Biological systems are affected by} disruptions to their dynamic homeostasis.

a. Disruptions at the molecular and cellular levels affect the health of the organism. To foster student understanding of this concept, instructors can choose an illustrative example such as:

- Physiological responses to toxic substances

- Dehydration

- Immunological responses to pathogens, toxins and allergens

b. Disruptions to ecosystems impact the dynamic homeostasis or balance of the ecosystem.

To foster student understanding of this concept, instructors can choose an illustrative example such as:

- Invasive and/or eruptive species

- Human impact

- Hurricanes, floods, earthquakes, volcanoes, fires

- Water limitation

- Salination

X No specific system is required for teaching the above concepts. Teachers are free to choose the system that best fosters student understanding. 
Learning Objective:

LO 2.28 The student is able to use representations or models to analyze quantitatively and qualitatively the effects of disruptions to dynamic homeostasis in biological systems. [See SP 1.4]

\section{Essential knowledge 2.D.4: Plants and animals have a variety of} chemical defenses against infections that affect dynamic homeostasis.

a. Plants, invertebrates and vertebrates have multiple, nonspecific immune responses. Students should be able to demonstrate understanding of the above concept by using an illustrative example such as:

- Invertebrate immune systems have nonspecific response mechanisms, but they lack pathogen-specific defense responses.

- Plant defenses against pathogens include molecular recognition systems with systemic responses; infection triggers chemical responses that destroy infected and adjacent cells, thus localizing the effects.

- Vertebrate immune systems have nonspecific and nonheritable defense mechanisms against pathogens.

b. Mammals use specific immune responses triggered by natural or artificial agents that disrupt dynamic homeostasis.

Evidence of student learning is a demonstrated understanding of each of the following:

1. The mammalian immune system includes two types of specific responses: cell mediated and humoral.

2. In the cell-mediated response, cytotoxic T cells, a type of lymphocytic white blood cell, "target" intracellular pathogens when antigens are displayed on the outside of the cells.

3. In the humoral response, B cells, a type of lymphocytic white blood cell, produce antibodies against specific antigens.

4. Antigens are recognized by antibodies to the antigen.

5. Antibodies are proteins produced by B cells, and each antibody is specific to a particular antigen.

6. A second exposure to an antigen results in a more rapid and enhanced immune response.

X Memorization of the structures of specific antibodies is beyond the scope of the course and the AP Exam. 
Learning Objectives:

LO 2.29 The student can create representations and models to describe immune responses. [See SP 1.1, 1.2]

LO 2.30 The student can create representations or models to describe nonspecific immune defenses in plants and animals.[See SP 1.1, 1.2]

\section{Enduring understanding 2.E: Many biological processes involved in growth, reproduction and dynamic homeostasis include temporal regulation and coordination.}

Multiple mechanisms regulate the timing and coordination of molecular, physiological and behavioral events that are necessary for an organism's development and survival. Cell differentiation results from the expression of genes for tissue-specific proteins, and the induction of transcription factors during development results in sequential gene expression. Cell differentiation also results from specific silencing of gene expression. For example, homeotic genes determine developmental patterns and sequences, and temperature and water availability determine seed germination in most plants. Genetic transplantation experiments support the link between gene expression, mutations and development. Programmed cell death (apoptosis) plays a role in normal development and differentiation (e.g., morphogenesis).

Physiological events in organisms can involve interactions between environmental stimuli and internal molecular signals; phototropism and photoperiodism in plants and circadian rhythms and seasonal responses in animals are examples.

Timing and coordination of behavior are also regulated by several means; individuals can act on information and communicate it to others, and responses to information are vital to natural selection. Examples include behaviors in animals triggered by environmental cues (hibernation, migration and estivation), courtship rituals and other visual displays, and photoperiodism in plants due to changes in critical night length.

Communication and cooperative behavior within or between populations contributes to the survival of individuals and the population. For example, changes in resource availability can lead to fruiting body formation in certain bacteria and fungi and niche partitioning.

Essential knowledge 2.E.1: Timing and coordination of specific events are necessary for the normal development of an organism, and these events are regulated by a variety of mechanisms.

a. Observable cell differentiation results from the expression of genes for tissuespecific proteins.

b. Induction of transcription factors during development results in sequential gene expression. 
Evidence of student learning is a demonstrated understanding of each of the following:

1. Homeotic genes are involved in developmental patterns and sequences.

2. Embryonic induction in development results in the correct timing of events.

3. Temperature and the availability of water determine seed germination in most plants.

4. Genetic mutations can result in abnormal development.

5. Genetic transplantation experiments support the link between gene expression and normal development.

6. Genetic regulation by microRNAs plays an important role in the development of organisms and the control of cellular functions.

c. Programmed cell death (apoptosis) plays a role in the normal development and differentiation.

Students should be able to demonstrate understanding of the above concept by using an illustrative example such as:

- Morphogenesis of fingers and toes

- Immune function

- C. elegans development

- Flower development

X Names of the specific stages of embryonic development are beyond the scope of the course and the AP Exam.

\section{Learning Objectives:}

LO 2.31 The student can connect concepts in and across domains to show that timing and coordination of specific events are necessary for normal development in an organism and that these events are regulated by multiple mechanisms. [See SP 7.2]

LO 2.32 The student is able to use a graph or diagram to analyze situations or solve problems (quantitatively or qualitatively) that involve timing and coordination of events necessary for normal development in an organism. [See SP 1.4]

LO 2.33 The student is able to justify scientific claims with scientific evidence to show that timing and coordination of several events are necessary for normal development in an organism and that these events are regulated by multiple mechanisms. [See SP 6.1]

LO 2.34 The student is able to describe the role of programmed cell death in development and differentiation, the reuse of molecules, and the maintenance of dynamic homeostasis. [See SP 7.1] 


\section{Essential knowledge 2.E.2: Timing and coordination of physiological} events are regulated by multiple mechanisms.

a. In plants, physiological events involve interactions between environmental stimuli and internal molecular signals. [See also 2.C.3]

Evidence of student learning is a demonstrated understanding of each of the following:

1. Phototropism, or the response to the presence of light

2. Photoperiodism, or the response to change in length of the night, that results in flowering in long-day and short-day plants

X Memorization of the names, molecular structures and specific effects of all plant hormones are beyond the scope of the course and the AP Exam.

b. In animals, internal and external signals regulate a variety of physiological responses that synchronize with environmental cycles and cues.

To foster student understanding of this concept, instructors can choose an illustrative example such as:

- Circadian rhythms, or the physiological cycle of about 24 hours that is present in all eukaryotes and persists even in the absence of external cues

- Diurnal/nocturnal and sleep/awake cycles

- Jet lag in humans

- Seasonal responses, such as hibernation, estivation and migration

- Release and reaction to pheromones

- Visual displays in the reproductive cycle

c. In fungi, protists and bacteria, internal and external signals regulate a variety of physiological responses that synchronize with environmental cycles and cues.

To foster student understanding of this concept, instructors can choose an illustrative example such as:

- Fruiting body formation in fungi, slime molds and certain types of bacteria

- Quorum sensing in bacteria

$\boldsymbol{X}$ Memorization of the names, molecular structures and specific effects of hormones or features of the brain responsible for these physiological phenomena is beyond the scope of the course and the AP Exam.

Learning Objectives:

LO 2.35 The student is able to design a plan for collecting data to support the scientific claim that the timing and coordination of physiological events involve regulation. [See SP 4.2] 
LO 2.36 The student is able to justify scientific claims with evidence to show how timing and coordination of physiological events involve regulation. [See SP 6.1]

LO 2.37 The student is able to connect concepts that describe mechanisms that regulate the timing and coordination of physiological events. [See SP 7.2]

Essential knowledge 2.E.3: Timing and coordination of behavior are regulated by various mechanisms and are important in natural selection.

a. Individuals can act on information and communicate it to others.

Evidence of student learning is a demonstrated understanding of each of the following:

1. Innate behaviors are behaviors that are inherited.

2. Learning occurs through interactions with the environment and other organisms.

b. Responses to information and communication of information are vital to natural selection. [See also 2.C.3]

Evidence of student learning is a demonstrated understanding of each of the following:

1. In phototropism in plants, changes in the light source lead to differential growth, resulting in maximum exposure of leaves to light for photosynthesis.

2. In photoperiodism in plants, changes in the length of night regulate flowering and preparation for winter.

3. Behaviors in animals are triggered by environmental cues and are vital to reproduction, natural selection and survival.

Students should be able to demonstrate understanding of the above concept by using an illustrative example such as:

- Hibernation

- Estivation

- Migration

- Courtship

4. Cooperative behavior within or between populations contributes to the survival of the populations.

Students should be able to demonstrate understanding of the above concept by using an illustrative example such as:

- Availability of resources leading to fruiting body formation in fungi and certain types of bacteria

- Niche and resource partitioning 
- Mutualistic relationships (lichens; bacteria in digestive tracts of animals; mycorrhizae)

- Biology of pollination

Learning Objectives:

LO 2.38 The student is able to analyze data to support the claim that responses to information and communication of information affect natural selection. [See SP 5.1]

LO 2.39 The student is able to justify scientific claims, using evidence, to describe how timing and coordination of behavioral events in organisms are regulated by several mechanisms. [See SP 6.1]

LO 2.40 The student is able to connect concepts in and across domain(s) to predict how environmental factors affect responses to information and change behavior. [See SP 7.2]

\section{Big Idea 3: Living systems store, retrieve, transmit and respond to information essential to life processes.}

Genetic information provides for continuity of life and, in most cases, this information is passed from parent to offspring via DNA. The double-stranded structure of DNA provides a simple and elegant solution for the transmission of heritable information to the next generation; by using each strand as a template, existing information can be preserved and duplicated with high fidelity within the replication process. However, the process of replication is imperfect, and errors occur through chemical instability and environmental impacts. Random changes in DNA nucleotide sequences lead to heritable mutations if they are not repaired. To protect against changes in the original sequence, cells have multiple mechanisms to correct errors. Despite the action of repair enzymes, some mutations are not corrected and are passed to subsequent generations. Changes in a nucleotide sequence, if present in a protein-coding region, can change the amino acid sequence of the polypeptide. In other cases, mutations can alter levels of gene expression or simply be silent. In order for information in DNA to direct cellular processes, information must be transcribed (DNA $\rightarrow$ RNA) and, in many cases, translated (RNA $\rightarrow$ protein). The products of transcription and translation play an important role in determining metabolism, i.e., cellular activities and phenotypes. Biotechnology makes it possible to directly engineer heritable changes in cells to yield novel protein products.

In eukaryotic organisms, heritable information is packaged into chromosomes that are passed to daughter cells. Alternating with interphase in the cell cycle, mitosis followed by cytokinesis provides a mechanism in which each daughter cell receives an identical and a complete complement of chromosomes. Mitosis ensures fidelity in the transmission of heritable information, and production of identical progeny allows organisms to grow, replace cells, and reproduce asexually. 
Sexual reproduction, however, involves the recombination of heritable information from both parents through fusion of gametes during fertilization. Meiosis followed by fertilization provides a spectrum of possible phenotypes in offspring and on which natural selection operates.

Mendel was able to describe a model of inheritance of traits, and his work represents an application of mathematical reasoning to a biological problem. However, most traits result from interactions of many genes and do not follow Mendelian patterns of inheritance. Understanding the genetic basis of specific phenotypes and their transmission in humans can raise social and ethical issues.

The expression of genetic material controls cell products, and these products determine the metabolism and nature of the cell. Gene expression is regulated by both environmental signals and developmental cascades or stages. Cell signaling mechanisms can also modulate and control gene expression. Thus, structure and function in biology involve two interacting aspects: the presence of necessary genetic information and the correct and timely expression of this information.

Genetic information is a repository of instructions necessary for the survival, growth and reproduction of the organism. Changes in information can often be observed in the organism due to changes in phenotypes. At the molecular level, these changes may result from mutations in the genetic material whereupon effects can often be seen when the information is processed to yield a polypeptide; the changes may be positive, negative or neutral to the organism. At the cellular level, errors in the transfer of genetic information through mitosis and meiosis can result in adverse changes to cellular composition. Additionally, environmental factors can influence gene expression.

Genetic variation is almost always advantageous for the long-term survival and evolution of a species. In sexually reproducing organisms, meiosis produces haploid gametes, and random fertilization produces diploid zygotes. In asexually reproducing organisms, variation can be introduced through mistakes in DNA replication or repair and through recombination; additionally, bacteria can transmit and/or exchange genetic information horizontally (between individuals in the same generation). Viruses have a unique mechanism of replication that is dependent on the host metabolic machinery. Viruses can introduce variation in the host genetic material through lysogenesis or latent infection.

To function in a biological system, cells communicate with other cells and respond to the external environment. Cell signaling pathways are determined by interacting signal and receptor molecules, and signaling cascades direct complex behaviors that affect physiological responses in the organism by altering gene expression or protein activity. Nonheritable information transmission influences behavior within and between cells, organisms and populations; these behaviors are directed by underlying genetic information, and responses to information are vital to natural selection and evolution. Animals have evolved sensory organs that detect and process external information. Nervous systems interface with these sensory and internal body systems, coordinating response and behavior; and this coordination occurs through the transmission and 
processing of signal information. Behavior in the individual serves to increase its fitness in the population while contributing to the overall survival of the population.

\section{Enduring understanding 3.A: Heritable information provides for continuity of life.}

The organizational basis of all living systems is heritable information. The proper storage and transfer of this information are critical for life to continue at the cell, organism and species levels. Reproduction occurs at the cellular and organismal levels. In order for daughter cells to continue subsequent generational cycles of reproduction or replication, each progeny needs to receive heritable genetic instructions from the parental source. This information is stored and passed to the subsequent generation via DNA. Viruses, as exceptional entities, can contain either DNA or RNA as heritable genetic information. The chemical structures of both DNA and RNA provide mechanisms that ensure information is preserved and passed to subsequent generations. There are important chemical and structural differences between DNA and RNA that result in different stabilities and modes of replication. In order for information stored in DNA to direct cellular processes, the information needs to be transcribed (DNA $\rightarrow$ RNA) and in many cases, translated (RNA $\rightarrow$ protein). The products of these processes determine metabolism and cellular activities and, thus, the phenotypes upon which evolution operates.

In eukaryotic organisms, genetic information is packaged into chromosomes, which carry essential heritable information that must be passed to daughter cells. Mitosis provides a mechanism that ensures each daughter cell receives an identical and complete set of chromosomes and that ensures fidelity in the transmission of heritable information. Mitosis allows for asexual reproduction of organisms in which daughter cells are genetically identical to the parental cell and allows for genetic information transfer to subsequent generations. Both unicellular and multicellular organisms have various mechanisms that increase genetic variation.

Sexual reproduction of diploid organisms involves the recombination of heritable information from both parents through fusion of gametes during fertilization. The two gametes that fuse to form a new progeny zygote each contain a single set (1n) of chromosomes. Meiosis reduces the number of chromosomes from diploid ( $2 n$ ) to haploid ( $1 n$ ) by following a single replication with two divisions. The random assortment of maternal and paternal chromosomes in meiosis and exchanges between sister chromosomes increase genetic variation; thus, the four gametes, while carrying the same number of chromosomes, are genetically unique with respect to individual alleles and allele combinations. The combination of these gametes at fertilization reestablishes the diploid nature of the organism and provides an additional mechanism for generating genetic variation, with every zygote being genetically different. Natural selection operates on populations through the phenotypic differences (traits) that individuals display; meiosis followed by fertilization provides a spectrum of possible phenotypes on which natural selection acts, and variation contributes to the long-term continuation of species.

Some phenotypes are products of action from single genes. These single gene traits 
provided the experimental system through which Mendel was able to describe a model of inheritance. The processes that chromosomes undergo during meiosis provide a mechanism that accounts for the random distribution of traits, the independence of traits, and the fact that some traits tend to stay together as they are transmitted from parent to offspring. Mendelian genetics can be applied to many phenotypes, including some human genetic disorders. Ethical, social and medical issues can surround such genetic disorders.

Whereas some traits are determined by the actions of single genes, most traits result from the interactions of multiple genes products or interactions between gene products and the environment. These traits often exhibit a spectrum of phenotypic properties that results in a wider range of observable traits, including weight, height and coat color in animals.

Essential knowledge 3.A.1: DNA, and in some cases RNA, is the primary source of heritable information.

a. Genetic information is transmitted from one generation to the next through DNA or RNA.

Evidence of student learning is a demonstrated understanding of each of the following:

1. Genetic information is stored in and passed to subsequent generations through DNA molecules and, in some cases, RNA molecules.

2. Noneukaryotic organisms have circular chromosomes, while eukaryotic organisms have multiple linear chromosomes, although in biology there are exceptions to this rule.

3. Prokaryotes, viruses and eukaryotes can contain plasmids, which are small extra-chromosomal, double-stranded circular DNA molecules.

4. The proof that DNA is the carrier of genetic information involved a number of important historical experiments. These include:

i. Contributions of Watson, Crick, Wilkins, and Franklin on the structure of DNA

ii. Avery-MacLeod-McCarty experiments

iii. Hershey-Chase experiment

5. DNA replication ensures continuity of hereditary information.

i. Replication is a semiconservative process; that is, one strand serves as the template for a new, complementary strand.

ii. Replication requires DNA polymerase plus many other essential cellular enzymes, occurs bidirectionally, and differs in the production of the leading and lagging strands.

6. Genetic information in retroviruses is a special case and has an alternate flow of information: from RNA to DNA, made possible by reverse transcriptase, an 
enzyme that copies the viral RNA genome into DNA. This DNA integrates into the host genome and becomes transcribed and translated for the assembly of new viral progeny. [See also 3.C.3]

X The names of the steps and particular enzymes involved, beyond DNA polymerase, ligase, RNA polymerase, helicase and topoisomerase, are outside the scope of the course for the purposes of the AP Exam.

b. DNA and RNA molecules have structural similarities and differences that define function. [See also 4.A.1]

Evidence of student learning is a demonstrated understanding of each of the following:

1. Both have three components - sugar, phosphate and a nitrogenous base which form nucleotide units that are connected by covalent bonds to form a linear molecule with 3 ' and 5 ' ends, with the nitrogenous bases perpendicular to the sugar-phosphate backbone.

2. The basic structural differences include:

i. DNA contains deoxyribose (RNA contains ribose).

ii. RNA contains uracil in lieu of thymine in DNA.

iii. DNA is usually double stranded, RNA is usually single stranded.

iv. The two DNA strands in double-stranded DNA are antiparallel in directionality.

3. Both DNA and RNA exhibit specific nucleotide base pairing that is conserved through evolution: adenine pairs with thymine or uracil (A-T or A-U) and cytosine pairs with guanine $(\mathrm{C}-\mathrm{G})$.

i. Purines ( $G$ and $A$ ) have a double ring structure.

ii. Pyrimidines ( $\mathrm{C}, \mathrm{T}$ and $\mathrm{U}$ ) have a single ring structure.

4. The sequence of the RNA bases, together with the structure of the RNA molecule, determines RNA function.

i. mRNA carries information from the DNA to the ribosome.

ii. tRNA molecules bind specific amino acids and allow information in the mRNA to be translated to a linear peptide sequence.

iii. rRNA molecules are functional building blocks of ribosomes.

iv. The role of RNAi includes regulation of gene expression at the level of mRNA transcription.

c. Genetic information flows from a sequence of nucleotides in a gene to a sequence of amino acids in a protein.

Evidence of student learning is a demonstrated understanding of each of the following:

1. The enzyme RNA-polymerase reads the DNA molecule in the $3^{\prime}$ to 5 ' direction 
and synthesizes complementary mRNA molecules that determine the order of amino acids in the polypeptide.

2. In eukaryotic cells the mRNA transcript undergoes a series of enzymeregulated modifications.

To foster student understanding of this concept, instructors can choose an illustrative example such as:

- Addition of a poly-A tail

- Addition of a GTP cap

- Excision of introns

3. Translation of the mRNA occurs in the cytoplasm on the ribosome.

4. In prokaryotic organisms, transcription is coupled to translation of the message. Translation involves energy and many steps, including initiation, elongation and termination.

X The details and names of the enzymes and factors involved in each of these steps are beyond the scope of the course and the $A P^{\oplus}$ Exam.

The salient features include:

i. The mRNA interacts with the rRNA of the ribosome to initiate translation at the (start) codon.

ii. The sequence of nucleotides on the mRNA is read in triplets called codons.

iii. Each codon encodes a specific amino acid, which can be deduced by using a genetic code chart. Many amino acids have more than one codon.

X Memorization of the genetic code is beyond the scope of the course and the AP Exam.

iv. tRNA brings the correct amino acid to the correct place on the mRNA.

v. The amino acid is transferred to the growing peptide chain.

vi. The process continues along the mRNA until a "stop" codon is reached.

vii. The process terminates by release of the newly synthesized peptide/protein.

d. Phenotypes are determined through protein activities.

To foster student understanding of this concept, instructors can choose an illustrative example such as:

- Enzymatic reactions

- Transport by proteins

- Synthesis

- Degradation

e. Genetic engineering techniques can manipulate the heritable information of DNA and, in special cases, RNA. 
To foster student understanding of this concept, instructors can choose an illustrative example such as:

- Electrophoresis

- Plasmid-based transformation

- Restriction enzyme analysis of DNA

- Polymerase Chain Reaction (PCR)

f. Illustrative examples of products of genetic engineering include:

- Genetically modified foods

- Transgenic animals

- Cloned animals

- Pharmaceuticals, such as human insulin or factor X

Learning Objectives:

LO 3.1 The student is able to construct scientific explanations that use the structures and mechanisms of DNA and RNA to support the claim that DNA and, in some cases, that RNA are the primary sources of heritable information. [See SP 6.5]

LO 3.2 The student is able to justify the selection of data from historical investigations that support the claim that DNA is the source of heritable information. [See SP 4.1]

LO 3.3 The student is able to describe representations and models that illustrate how genetic information is copied for transmission between generations.

[See SP 1.2]

LO 3.4 The student is able to describe representations and models illustrating how genetic information is translated into polypeptides. [See SP 1.2]

LO 3.5 The student can justify the claim that humans can manipulate heritable information by identifying at least two commonly used technologies. [See SP 6.4]

LO 3.6 The student can predict how a change in a specific DNA or RNA sequence can result in changes in gene expression. [See SP 6.4]

Essential knowledge 3.A.2: In eukaryotes, heritable information is passed to the next generation via processes that include the cell cycle and mitosis or meiosis plus fertilization.

a. The cell cycle is a complex set of stages that is highly regulated with checkpoints, which determine the ultimate fate of the cell.

Evidence of student learning is a demonstrated understanding of each of the following:

1. Interphase consists of three phases: growth, synthesis of DNA, preparation for mitosis. 
2. The cell cycle is directed by internal controls or checkpoints. Internal and external signals provide stop-and-go signs at the checkpoints.

To foster student understanding of this concept, instructors can choose an illustrative example such as:

- Mitosis-promoting factor (MPF)

- Action of platelet-derived growth factor (PDGF)

- Cancer results from disruptions in cell cycle control

3. Cyclins and cyclin-dependent kinases control the cell cycle.

X Knowledge of any one cyclin-CdK pair or growth factor is beyond the scope of the course and the AP Exam.

4. Mitosis alternates with interphase in the cell cycle.

5. When a cell specializes, it often enters into a stage where it no longer divides, but it can reenter the cell cycle when given appropriate cues. Nondividing cells may exit the cell cycle; or hold at a particular stage in the cell cycle.

b. Mitosis passes a complete genome from the parent cell to daughter cells.

Evidence of student learning is a demonstrated understanding of each of the following:

1. Mitosis occurs after DNA replication.

2. Mitosis followed by cytokinesis produces two genetically identical daughter cells.

3. Mitosis plays a role in growth, repair, and asexual reproduction

4. Mitosis is a continuous process with observable structural features along the mitotic process. Evidence of student learning is demonstrated by knowing the order of the processes (replication, alignment, separation).

$\mathbf{X}$ Memorization of the names of the phases of mitosis is beyond the scope of the course and the AP Exam.

c. Meiosis, a reduction division, followed by fertilization ensures genetic diversity in sexually reproducing organisms.

Evidence of student learning is a demonstrated understanding of each of the following:

1. Meiosis ensures that each gamete receives one complete haploid (1n) set of chromosomes.

2. During meiosis, homologous chromosomes are paired, with one homologue originating from the maternal parent and the other from the paternal parent. Orientation of the chromosome pairs is random with respect to the cell poles.

3. Separation of the homologous chromosomes ensures that each gamete 
receives a haploid (1n) set of chromosomes composed of both maternal and paternal chromosomes.

4. During meiosis, homologous chromatids exchange genetic material via a process called "crossing over," which increases genetic variation in the resultant gametes. [See also 3.C.2]

5. Fertilization involves the fusion of two gametes, increases genetic variation in populations by providing for new combinations of genetic information in the zygote, and restores the diploid number of chromosomes.

Learning Objectives:

LO 3.7 The student can make predictions about natural phenomena occurring during the cell cycle. [See SP 6.4]

LO 3.8 The student can describe the events that occur in the cell cycle. [See SP 1.2]

LO 3.9 The student is able to construct an explanation, using visual representations or narratives, as to how DNA in chromosomes is transmitted to the next generation via mitosis, or meiosis followed by fertilization. [See SP 6.2]

LO 3.10 The student is able to represent the connection between meiosis and increased genetic diversity necessary for evolution. [See SP 7.1]

LO 3.11 The student is able to evaluate evidence provided by data sets to support the claim that heritable information is passed from one generation to another generation through mitosis, or meiosis followed by fertilization. [See SP 5.3]

\section{Essential knowledge 3.A.3: The chromosomal basis of inheritance provides an understanding of the pattern of passage (transmission) of genes from parent to offspring.}

a. Rules of probability can be applied to analyze passage of single gene traits from parent to offspring.

b. Segregation and independent assortment of chromosomes result in genetic variation. Evidence of student learning is a demonstrated understanding of each of the following:

1. Segregation and independent assortment can be applied to genes that are on different chromosomes.

2. Genes that are adjacent and close to each other on the same chromosome tend to move as a unit; the probability that they will segregate as a unit is a function of the distance between them.

3. The pattern of inheritance (monohybrid, dihybrid, sex-linked, and genes linked 
on the same homologous chromosome) can often be predicted from data that gives the parent genotype/phenotype and/or the offspring phenotypes/genotypes.

c. Certain human genetic disorders can be attributed to the inheritance of single gene traits or specific chromosomal changes, such as nondisjunction.

To foster student understanding of this concept, instructors can choose an illustrative example such as:

- Sickle cell anemia

- Tay-Sachs disease

- Huntington's disease

- X-linked color blindness

- Trisomy 21/Down syndrome

- Klinefelter's syndrome

d. Many ethical, social and medical issues surround human genetic disorders.

To foster student understanding of this concept, instructors can choose an illustrative example such as:

- Reproduction issues

- Civic issues such as ownership of genetic information, privacy, historical contexts, etc.

Learning Objectives:

LO 3.12 The student is able to construct a representation that connects the process of meiosis to the passage of traits from parent to offspring. [See SP 1.1, 7.2]

LO 3.13 The student is able to pose questions about ethical, social or medical issues surrounding human genetic disorders. [See SP 3.1]

LO 3.14 The student is able to apply mathematical routines to determine Mendelian patterns of inheritance provided by data sets. [See SP 2.2]

Essential knowledge 3.A.4: The inheritance pattern of many traits cannot be explained by simple Mendelian genetics.

a. Many traits are the product of multiple genes and/or physiological processes.

Evidence of student learning is a demonstrated understanding of the following:

1. Patterns of inheritance of many traits do not follow ratios predicted by Mendel's laws and can be identified by quantitative analysis, where observed phenotypic ratios statistically differ from the predicted ratios. 
b. Some traits are determined by genes on sex chromosomes.

To foster student understanding of this concept, instructors can choose an illustrative example such as:

- Sex-linked genes reside on sex chromosomes (X in humans).

- In mammals and flies, the Y chromosome is very small and carries few genes.

- In mammals and flies, females are XX and males are XY; as such, X-linked recessive traits are always expressed in males.

- Some traits are sex limited, and expression depends on the sex of the individual, such as milk production in female mammals and pattern baldness in males.

c. Some traits result from nonnuclear inheritance.

Evidence of student learning is a demonstrated understanding of each of the following:

1. Chloroplasts and mitochondria are randomly assorted to gametes and daughter cells; thus, traits determined by chloroplast and mitochondrial DNA do not follow simple Mendelian rules.

2. In animals, mitochondrial DNA is transmitted by the egg and not by sperm; as such, mitochondrial-determined traits are maternally inherited.

X Epistasis and pleiotropy are beyond the scope of the course and the AP Exam.

Learning Objectives:

LO 3.15 The student is able to explain deviations from Mendel's model of the inheritance of traits. [See SP 6.5]

LO 3.16 The student is able to explain how the inheritance patterns of many traits cannot be accounted for by Mendelian genetics. [See SP 6.3]

LO 3.17 The student is able to describe representations of an appropriate example of inheritance patterns that cannot be explained by Mendel's model of the inheritance of traits. [See SP 1.2]

\section{Enduring understanding 3.B: Expression of genetic information involves cellular and molecular mechanisms.}

Structure and function in biology result from the presence of genetic information and the correct expression of this information. The expression of the genetic material controls cell products, and these products determine the metabolism and nature of the cell. Most cells within an organism contain the same set of genetic instructions, but the differential expression of specific genes determines the specialization of cells. Some genes are continually expressed, while the expression of most is regulated; regulation allows 
more efficient energy utilization, resulting in increased metabolic fitness. Gene expression is controlled by environmental signals and developmental cascades that involve both regulatory and structural genes. A variety of different gene regulatory systems are found in nature. Two of the best studied are the inducible and the repressible regulatory systems (i.e., operons) in bacteria, and several regulatory pathways that are conserved across phyla use a combination of positive and negative regulatory motifs. In eukaryotes, gene regulation and expression are more complex and involve many factors, including a suite of regulatory molecules.

Multicellular organisms have developmental pathways from zygote to adult, yet all cells in the organism start with the same complement of DNA. The developmental sequences are predominately determined and programmed by differential gene expression. Which gene gets expressed and the level of expression are determined by both internal and external signals. In multicellular organisms, cell-to-cell interactions and cell-to-cell signaling via small molecules modulate and control gene expression and cell function. For example, morphogens help to determine spatial development, and hormones can influence cell metabolism. Developmental gene sequences have an evolutionary origin and are conserved across species; for example, HOX genes are present in genome sequences from Drosophila to humans. Errors or changes in regulation of genes involved in development often lead to severe, detrimental and even bizarre consequences.

\section{Essential knowledge 3.B.1: Gene regulation results in differential gene expression, leading to cell specialization.}

a. Both DNA regulatory sequences, regulatory genes, and small regulatory RNAs are involved in gene expression.

Evidence of student learning is a demonstrated understanding of each of the following:

1. Regulatory sequences are stretches of DNA that interact with regulatory proteins to control transcription.

To foster student understanding of this concept, instructors can choose an illustrative example such as:

- Promoters

- Terminators

- Enhancers

2. A regulatory gene is a sequence of DNA encoding a regulatory protein or RNA.

b. Both positive and negative control mechanisms regulate gene expression in bacteria and viruses.

Evidence of student learning is a demonstrated understanding of each of the following:

1. The expression of specific genes can be turned on by the presence of an inducer. 
2. The expression of specific genes can be inhibited by the presence of a repressor.

3. Inducers and repressors are small molecules that interact with regulatory proteins and/or regulatory sequences.

4. Regulatory proteins inhibit gene expression by binding to DNA and blocking transcription (negative control).

5. Regulatory proteins stimulate gene expression by binding to DNA and stimulating transcription (positive control) or binding to repressors to inactivate repressor function.

6. Certain genes are continuously expressed; that is, they are always turned "on," e.g., the ribosomal genes.

c. In eukaryotes, gene expression is complex and control involves regulatory genes, regulatory elements and transcription factors that act in concert.

Evidence of student learning is a demonstrated understanding of each of the following:

1. Transcription factors bind to specific DNA sequences and/or other regulatory proteins.

2. Some of these transcription factors are activators (increase expression), while others are repressors (decrease expression).

3. The combination of transcription factors binding to the regulatory regions at any one time determines how much, if any, of the gene product will be produced.

d. Gene regulation accounts for some of the phenotypic differences between organisms with similar genes.

\section{Learning Objectives:}

LO 3.18 The student is able to describe the connection between the regulation of gene expression and observed differences between different kinds of organisms. [See SP 7.1]

LO 3.19 The student is able to describe the connection between the regulation of gene expression and observed differences between individuals in a population. [See SP 7.1]

LO 3.20 The student is able to explain how the regulation of gene expression is essential for the processes and structures that support efficient cell function. [See SP 6.2]

LO 3.21 The student can use representations to describe how gene regulation influences cell products and function. [See SP 1.4] 


\section{Essential knowledge 3.B.2: A variety of intercellular and intracellular} signal transmissions mediate gene expression.

a. Signal transmission within and between cells mediates gene expression.

To foster student understanding of this concept, instructors can choose an illustrative example such as:

- Cytokines regulate gene expression to allow for cell replication and division.

- Mating pheromones in yeast trigger mating gene expression.

- Levels of cAMP regulate metabolic gene expression in bacteria.

- Expression of the SRY gene triggers the male sexual development pathway in animals.

- Ethylene levels cause changes in the production of different enzymes, allowing fruits to ripen.

- Seed germination and gibberellin.

b. Signal transmission within and between cells mediates cell function.

To foster student understanding of this concept, instructors can choose an illustrative example such as:

- Mating pheromones in yeast trigger mating genes expression and sexual reproduction.

- Morphogens stimulate cell differentiation and development.

- Changes in p53 activity can result in cancer.

- HOX genes and their role in development.

Learning Objectives:

LO 3.22 The student is able to explain how signal pathways mediate gene expression, including how this process can affect protein production. [See SP 6.2]

LO 3.23 The student can use representations to describe mechanisms of the regulation of gene expression. [See SP 1.4]

\section{Enduring understanding 3.C: The processing of genetic information is imperfect and is a source of genetic variation.}

Genetic information is a set of instructions necessary for the survival, growth and reproduction of an organism. In order for the information to be useful, it needs to be processed by the cell. Processing includes replication, decoding and transfer of the information. When genetic information changes, either through natural processes or genetic engineering, the results may be observable changes in the organism. At the molecular level, these changes may be the result of mutations in the genetic material, the 
effects of which may be seen when the information is processed to yield a nucleic acid or a polypeptide. The processes of transcription, mRNA processing and translation are imperfect, and errors can occur and may, in certain cases, alter phenotypes. However, these errors are random and are not heritable except in the case of RNA viruses where the random errors change the genetic information of the virus. External factors in the environment can affect the degree of, or the potential for increased probability for, errors in the information and processing. Cellular mechanisms that usually correct errors have evolved. Genetic variations at the genome level, when expressed as phenotypes, are subject to natural selection.

Since all organisms, as well as viruses, exist in a dynamic environment, mechanisms that increase genetic variation are vital for a species' ability to adapt to a changing environment. In a meiotic organism, the transfer process, whereby each gamete receives one set of chromosomes, ensures that this set is unique and different from that of the parent. Random processes such as the transposition of DNA regions ("jumping genes") occur in all biological domains. Bacteria divide by binary fission and do not have the random assortment processes that occur in eukaryotic organisms. Nonetheless, mechanisms have evolved in bacteria that ensure genetic variation beyond the variation that is introduced through normal DNA metabolism, e.g., replication, repair and recombination. Bacterial genetic information can be transmitted or exchanged laterally through a variety of processes, including conjugation, transduction and transformation. This type of exchange yields rapid dissemination of new phenotypes within and between bacterial populations, allowing for rapid evolution.

The basic structure of viruses includes a protein capsid that surrounds and protects the genetic information (genome) that can be either DNA or RNA. Viruses have a mechanism of replication that is dependent on the host metabolic machinery to produce necessary viral components and viral genetic material. Some classes of viruses use RNA without a DNA intermediate; however, retroviruses, such as HIV, use a DNA intermediate for replication of their genetic material. Some viruses introduce variation into the host genetic material. When the host is bacterial, it is referred to as lysogenesis; whereas in eukaryotic cells, this is referred to as transformation. Since viruses use the host metabolic pathways, they experience the same potential as the host for genetic variation that results from DNA metabolism.

\section{Essential knowledge 3.C.1: Changes in genotype can result in changes in phenotype.}

a. Alterations in a DNA sequence can lead to changes in the type or amount of the protein produced and the consequent phenotype. [See also 3.A.1]

Evidence of student learning is a demonstrated understanding of the following:

1. DNA mutations can be positive, negative or neutral based on the effect or the lack of effect they have on the resulting nucleic acid or protein and the phenotypes that are conferred by the protein. 
b. Errors in DNA replication or DNA repair mechanisms, and external factors, including radiation and reactive chemicals, can cause random changes, e.g., mutations in the DNA.

Evidence of student learning is a demonstrated understanding of the following:

1. Whether or not a mutation is detrimental, beneficial or neutral depends on the environmental context. Mutations are the primary source of genetic variation.

c. Errors in mitosis or meiosis can result in changes in phenotype.

Evidence of student learning is a demonstrated understanding of each of the following:

1. Changes in chromosome number often result in new phenotypes, including sterility caused by triploidy and increased vigor of other polyploids.

[See also 3.A.2]

2. Changes in chromosome number often result in human disorders with developmental limitations, including Trisomy 21 (Down syndrome) and XO (Turner syndrome). [See also 3.A.2, 3.A.3]

d. Changes in genotype may affect phenotypes that are subject to natural selection. Genetic changes that enhance survival and reproduction can be selected by environmental conditions. [See also 1.A.2, 1.C.3]

To foster student understanding of this concept, instructors can choose an illustrative example such as:

- Antibiotic resistance mutations

- Pesticide resistance mutations

- Sickle cell disorder and heterozygote advantage

Evidence of student learning is a demonstrated understanding of the following:

1. Selection results in evolutionary change.

Learning Objectives:

LO 3.24 The student is able to predict how a change in genotype, when expressed as a phenotype, provides a variation that can be subject to natural selection.

[See SP 6.4, 7.2]

LO 3.25 The student can create a visual representation to illustrate how changes in a DNA nucleotide sequence can result in a change in the polypeptide produced. [See SP 1.1]

LO 3.26 The student is able to explain the connection between genetic variations in organisms and phenotypic variations in populations. [See SP 7.2] 
Essential knowledge 3.C.2: Biological systems have multiple processes that increase genetic variation.

a. The imperfect nature of DNA replication and repair increases variation.

b. The horizontal acquisitions of genetic information primarily in prokaryotes via transformation (uptake of naked DNA), transduction (viral transmission of genetic information), conjugation (cell-to-cell transfer) and transposition (movement of DNA segments within and between DNA molecules) increase variation. [See also 1.B.3]

$\boldsymbol{X}$ Details and specifics about the various processes are beyond the scope of the course and the AP Exam.

c. Sexual reproduction in eukaryotes involving gamete formation, including crossing-over during meiosis and the random assortment of chromosomes during meiosis, and fertilization serve to increase variation. Reproduction processes that increase genetic variation are evolutionarily conserved and are shared by various organisms. [See also 1.B.1, 3.A.2, 4.C.2, 4. C3]

$\boldsymbol{X}$ The details of sexual reproduction cycles in various plants and animals are beyond the scope of the course and the AP Exam. However, the similarities of the processes that provide for genetic variation are relevant and should be the focus of instruction.

Learning Objectives:

LO 3.27 The student is able to compare and contrast processes by which genetic variation is produced and maintained in organisms from multiple domains. [See SP 7.2]

LO 3.28 The student is able to construct an explanation of the multiple processes that increase variation within a population. [See SP 6.2]

Essential knowledge 3.C.3: Viral replication results in genetic variation, and viral infection can introduce genetic variation into the hosts.

a. Viral replication differs from other reproductive strategies and generates genetic variation via various mechanisms. [See also 1.B.3]

Evidence of student learning is a demonstrated understanding of each of the following:

1. Viruses have highly efficient replicative capabilities that allow for rapid evolution and acquisition of new phenotypes.

2. Viruses replicate via a component assembly model allowing one virus to produce many progeny simultaneously via the lytic cycle.

3. Virus replication allows for mutations to occur through usual host pathways. 
4. RNA viruses lack replication error-checking mechanisms, and thus have higher rates of mutation.

5. Related viruses can combine/recombine information if they infect the same host cell.

6. HIV is a well-studied system where the rapid evolution of a virus within the host contributes to the pathogenicity of viral infection.

b. The reproductive cycles of viruses facilitate transfer of genetic information.

Evidence of student learning is a demonstrated understanding of each of the following:

1. Viruses transmit DNA or RNA when they infect a host cell. [See also 1.B.3]

To foster student understanding of this concept, instructors can choose an illustrative example such as:

- Transduction in bacteria

- Transposons present in incoming DNA

2. Some viruses are able to integrate into the host DNA and establish a latent (lysogenic) infection. These latent viral genomes can result in new properties for the host such as increased pathogenicity in bacteria.

Learning Objectives:

LO 3.29 The student is able to construct an explanation of how viruses introduce genetic variation in host organisms. [See SP 6.2]

LO 3.30 The student is able to use representations and appropriate models to describe how viral replication introduces genetic variation in the viral population. [See SP 1.4]

\section{Enduring understanding 3.D: Cells communicate by generating, transmitting and receiving chemical signals.}

For cells to function in a biological system, they must communicate with other cells and respond to their external environment. Cell-to-cell communication is ubiquitous in biological systems, from archaea and bacteria to multicellular organisms. The basic chemical processes by which cells communicate are shared across evolutionary lines of descent, and communication schemes are the products of evolution. Cell-to-cell communication is a component of higherorder biological organization and responses. In multicellular organisms, cell-to-cell and environment-to-cell chemical signaling pathways direct complex processes, ranging from cell and organ differentiation to whole organism physiological responses and behaviors. Certain signal pathways involve direct cell-to-cell contact, operate over very short distances, and may be determined by the structure of the organism or organelle, including plasmodesmata in plants and receptor-to-recognition protein interaction in the vertebrate immune system. 
Chemical signals allow cells to communicate without physical contact. The distance between the signal generating cell(s) and the responding cell can be small or large. In this type of signaling pathway, there is often a gradient response, and threshold concentrations are required to trigger the communication pathway.

Chemical signaling pathways in cells are determined by the properties of the molecules involved, the concentrations of signal and receptor molecules, and the binding affinities (fit) between signal and receptor. The signal can be a molecule or a physical or environmental factor. At the cellular level, the receptor is a protein with specificity for the signal molecule; this allows the response pathway to be specific and appropriate. The receptor protein often is the initiation point for a signal cascade that ultimately results in a change in gene expression, protein activity, or physiological state of the cell or organism, including cell death (apoptosis). Defects in any part of the signal pathway often lead to severe or detrimental conditions such as faulty development, metabolic diseases, cancer or death.

Understanding signaling pathways allows humans to modify and manipulate biological systems and physiology. An understanding of the human endocrine system, for example, allowed the development of birth control methods, as well as medicines that control depression, blood pressure and metabolism. Other examples include the ability to control/ modify ripening in fruit, agricultural production (growth hormones) and biofilm control.

Essential knowledge 3.D.1: Cell communication processes share common features that reflect a shared evolutionary history.

a. Communication involves transduction of stimulatory or inhibitory signals from other cells, organisms or the environment. [See also 1.B.1]

b. Correct and appropriate signal transduction processes are generally under strong selective pressure.

c. In single-celled organisms, signal transduction pathways influence how the cell responds to its environment.

To foster student understanding of this concept, instructors can choose an illustrative example such as:

- Use of chemical messengers by microbes to communicate with other nearby cells and to regulate specific pathways in response to population density (quorum sensing)

- Use of pheromones to trigger reproduction and developmental pathways

- Response to external signals by bacteria that influences cell movement

d. In multicellular organisms, signal transduction pathways coordinate the activities within individual cells that support the function of the organism as a whole.

To foster student understanding of this concept, instructors can choose an illustrative example such as: 
- Epinephrine stimulation of glycogen breakdown in mammals

- Temperature determination of sex in some vertebrate organisms

- DNA repair mechanisms

Learning Objectives:

LO 3.31 The student is able to describe basic chemical processes for cell communication shared across evolutionary lines of descent. [See SP 7.2]

LO 3.32 The student is able to generate scientific questions involving cell communication as it relates to the process of evolution. [See SP 3.1]

LO 3.33 The student is able to use representation(s) and appropriate models to describe features of a cell signaling pathway. [See SP 1.4]

Essential knowledge 3.D.2: Cells communicate with each other through direct contact with other cells or from a distance via chemical signaling.

a. Cells communicate by cell-to-cell contact.

To foster student understanding of this concept, instructors can choose an illustrative example such as:

- Immune cells interact by cell-cell contact, antigen-presenting cells (APCs), helper T-cells and killer T-cells. [See also 2.D.4]

- Plasmodesmata between plant cells that allow material to be transported from cell to cell.

b. Cells communicate over short distances by using local regulators that target cells in the vicinity of the emitting cell.

To foster student understanding of this concept, instructors can choose an illustrative example such as:

- Neurotransmitters

- Plant immune response

- Quorum sensing in bacteria

- Morphogens in embryonic development

c. Signals released by one cell type can travel long distances to target cells of another cell type.

Evidence of student learning is a demonstrated understanding of the following:

1. Endocrine signals are produced by endocrine cells that release signaling molecules, which are specific and can travel long distances through the blood to reach all parts of the body. 
To foster student understanding of this concept, instructors can choose an illustrative example such as:

- Insulin

- Human growth hormone

- Thyroid hormones

- Testosterone

- Estrogen

X No specific system, with the exception of the endocrine system, is required for teaching the concepts in 3.D.2. Teachers are free to choose a system that best fosters student understanding. Study of the nervous and immune systems is required for concepts detailed in 3.E.2 and 2.D.4.

\section{Learning Objectives:}

LO 3.34 The student is able to construct explanations of cell communication through cell-to-cell direct contact or through chemical signaling. [See SP 6.2]

LO 3.35 The student is able to create representation(s) that depict how cell-to-cell communication occurs by direct contact or from a distance through chemical signaling. [See SP 1.1]

Essential knowledge 3.D.3: Signal transduction pathways link signal reception with cellular response.

a. Signaling begins with the recognition of a chemical messenger, a ligand, by a receptor protein.

Evidence of student learning is a demonstrated understanding of each of the following:

1. Different receptors recognize different chemical messengers, which can be peptides, small chemicals or proteins, in a specific one-to-one relationship.

2. A receptor protein recognizes signal molecules, causing the receptor protein's shape to change, which initiates transduction of the signal.

To foster student understanding of this concept, instructors can choose an illustrative example such as:

- G-protein linked receptors

- Ligand-gated ion channels

- Receptor tyrosine kinases

X No particular system is required for teaching the concepts above. Teachers are free to choose a system that best fosters student understanding. 
b. Signal transduction is the process by which a signal is converted to a cellular response.

Evidence of student learning is a demonstrated understanding of each of the following:

1. Signaling cascades relay signals from receptors to cell targets, often amplifying the incoming signals, with the result of appropriate responses by the cell.

2. Second messengers are often essential to the function of the cascade.

To foster student understanding of this concept, instructors can choose an illustrative example such as:

- Ligand-gated ion channels

- Second messengers, such as cyclic GMP, cyclic AMP calcium ions $\left(\mathrm{Ca}^{2+}\right)$, and inositol triphosphate $\left(\mathrm{IP}_{3}\right)$

3. Many signal transduction pathways include:

i. Protein modifications (an illustrative example could be how methylation changes the signaling process)

ii. Phosphorylation cascades in which a series of protein kinases add a phosphate group to the next protein in the cascade sequence

\section{Learning Objectives:}

LO 3.36 The student is able to describe a model that expresses the key elements of signal transduction pathways by which a signal is converted to a cellular response. [See SP 1.5]

\section{Essential knowledge 3.D.4: Changes in signal transduction pathways can alter cellular response.}

a. Conditions where signal transduction is blocked or defective can be deleterious, preventative or prophylactic.

To foster student understanding of this concept, instructors can choose an illustrative example such as:

- Diabetes, heart disease, neurological disease, autoimmune disease, cancer, cholera

- Effects of neurotoxins, poisons, pesticides

- Drugs (Hypertensives, Anesthetics, Antihistamines and Birth Control Drugs)

X Specific mechanisms of these diseases and action of drugs are beyond the scope of the course and the AP Exam. 
Learning Objectives:

LO 3.37 The student is able to justify claims based on scientific evidence that changes in signal transduction pathways can alter cellular response. [See SP 6.1]

LO 3.38 The student is able to describe a model that expresses key elements to show how change in signal transduction can alter cellular response. [See SP 1.5]

LO 3.39 The student is able to construct an explanation of how certain drugs affect signal reception and, consequently, signal transduction pathways. [See SP 6.2]

\section{Enduring understanding 3.E: Transmission of information results in changes within and between biological systems.}

Evolution operates on genetic information that is passed to subsequent generations. However, transmission of nonheritable information also determines critical roles that influence behavior within and between cells, organisms and populations. These responses are dependent upon or influenced by underlying genetic information, and decoding in many cases is complex and affected by external conditions. For example, biological rhythms, mating behaviors, flowering, animal communications and social structures are dependent on and elicited by external signals and may encompass a range of responses and behaviors.

Organ systems have evolved that sense and process external information to facilitate and enhance survival, growth and reproduction in multicellular organisms. These include sensory systems that monitor and detect physical and chemical signals from the environment and other individuals in the population and that influence an animal's wellbeing. The nervous system interacts with sensory and internal body systems to coordinate responses and behaviors, ranging from movement to metabolism to respiration. Loss of function and coordination within the nervous system often results in severe consequences, including changes in behavior, loss of body functions and even death.

Knowledge and understanding of the structures and functions of the nervous system are needed to understand this coordination. The features of an animal's nervous system are evolutionarily conserved, with the basic cellular structure of neurons the same across species. The physiological and cellular processes for signal formation and propagation involve specialized membrane proteins, signaling molecules and ATP. Neurological signals can operate and coordinate responses across significant distances within an organism. The brain serves as a master neurological center for processing information and directing responses, and different regions of the brain serve different functions. Structures and associated functions for animal brains are products of evolution, and increasing complexity follows evolutionary lines.

Populations of organisms exist in communities. Individual behavior influences population behavior, and both are the products of information recognition, processing and transmission. Communication among individuals within a population may increase the long-term success of 
the population. Cooperative behavior within a population provides benefits to the population and to the individuals within the population. Examples of benefits include protection from predators, acquisition of prey and resources, sexual reproduction, recognition of offspring and genetic relatedness, and transmission of learned responses.

\section{Essential knowledge 3.E.1: Individuals can act on information and communicate it to others.}

a. Organisms exchange information with each other in response to internal changes and external cues, which can change behavior.

Students should be able to demonstrate understanding of the above concept by using an illustrative example such as:

- Fight or flight response

- Predator warnings

- Protection of young

- Plant-plant interactions due to herbivory

- Avoidance responses

b. Communication occurs through various mechanisms.

Evidence of student learning is a demonstrated understanding of each of the following:

1. Living systems have a variety of signal behaviors or cues that produce changes in the behavior of other organisms and can result in differential reproductive success. To foster student understanding of this concept, instructors can choose an illustrative example such as:

- Herbivory responses

- Territorial marking in mammals

- Coloration in flowers

2. Animals use visual, audible, tactile, electrical and chemical signals to indicate dominance, find food, establish territory and ensure reproductive success. To foster student understanding of this concept, instructors can choose an illustrative example such as:

- Bee dances

- Birds songs

- Territorial marking in mammals

- Pack behavior in animals

- Herd, flock, and schooling behavior in animals

- Predator warning 
- Colony and swarming behavior in insects

- Coloration

c. Responses to information and communication of information are vital to natural selection and evolution. [See also 1.A.2]

Evidence of student learning is a demonstrated understanding of the following:

1. Natural selection favors innate and learned behaviors that increase survival and reproductive fitness.

Students should be able to demonstrate understanding of the above concept by using an illustrative example such as:

- Parent and offspring interactions

- Migration patterns

- Courtship and mating behaviors

- Foraging in bees and other animals

- Avoidance behavior to electric fences, poisons, or traps

2. Cooperative behavior tends to increase the fitness of the individual and the survival of the population.

To foster student understanding of this concept, instructors can choose an illustrative example such as:

- Pack behavior in animals

- Herd, flock and schooling behavior in animals

- Predator warning

- Colony and swarming behavior in insects

$\mathbf{X}$ The details of the various communications and community behavioral systems are beyond the scope of the course and the AP Exam.

Learning Objectives:

LO 3.40 The student is able to analyze data that indicate how organisms exchange information in response to internal changes and external cues, and which can change behavior. [See SP 5.1]

LO 3.41 The student is able to create a representation that describes how organisms exchange information in response to internal changes and external cues, and which can result in changes in behavior. [See SP 1.1]

LO 3.42 The student is able to describe how organisms exchange information in response to internal changes or environmental cues. [See SP 7.1] 
Essential knowledge 3.E.2: Animals have nervous systems that detect external and internal signals, transmit and integrate information, and produce responses.

a. The neuron is the basic structure of the nervous system that reflects function. Evidence of student learning is a demonstrated understanding of each of the following:

1. A typical neuron has a cell body, axon and dendrites. Many axons have a myelin sheath that acts as an electrical insulator.

2. The structure of the neuron allows for the detection, generation, transmission and integration of signal information.

3. Schwann cells, which form the myelin sheath, are separated by gaps of unsheathed axon over which the impulse travels as the signal propagates along the neuron.

b. Action potentials propagate impulses along neurons.

Evidence of student learning is a demonstrated understanding of each of the following:

1. Membranes of neurons are polarized by the establishment of electrical potentials across the membranes.

2. In response to a stimulus, $\mathrm{Na}^{+}$and $\mathrm{K}^{+}$gated channels sequentially open and cause the membrane to become locally depolarized.

3. $\mathrm{Na}^{+} / \mathrm{K}^{+}$pumps, powered by ATP, work to maintain membrane potential.

c. Transmission of information between neurons occurs across synapses.

Evidence of student learning is a demonstrated understanding of each of the following:

1. In most animals, transmission across synapses involves chemical messengers called neurotransmitters.

To foster student understanding of this concept, instructors can choose an illustrative example such as:

- Acetylcholine

- Epinephrine

- Norepinephrine

- Dopamine

- Serotonin

- GABA

2. Transmission of information along neurons and synapses results in a response.

3. The response can be stimulatory or inhibitory. 
d. Different regions of the vertebrate brain have different functions.

To foster student understanding of this concept, instructors can choose an illustrative example such as:

- Vision

- Hearing

- Muscle movement

- Abstract thought and emotions

- Neuro-hormone production

- Forebrain (cerebrum), midbrain (brainstem) and hindbrain (cerebellum)

- Right and left cerebral hemispheres in humans

$\mathbf{X}$ The types of nervous systems, development of the human nervous system, details of the various structures and features of the brain parts, and details of specific neurologic processes are beyond the scope of the course and the AP Exam.

\section{Learning Objectives:}

LO 3.43 The student is able to construct an explanation, based on scientific theories and models, about how nervous systems detect external and internal signals, transmit and integrate information, and produce responses. [See SP 6.2, 7.1]

LO 3.44 The student is able to describe how nervous systems detect external and internal signals. [See SP 1.2]

LO 3.45 The student is able to describe how nervous systems transmit information. [See SP 1.2]

LO 3.46 The student is able to describe how the vertebrate brain integrates information to produce a response. [See SP 1.2]

LO 3.47 The student is able to create a visual representation of complex nervous systems to describe/explain how these systems detect external and internal signals, transmit and integrate information, and produce responses. [See SP 1.1]

LO 3.48 The student is able to create a visual representation to describe how nervous systems detect external and internal signals. [See SP 1.1]

LO 3.49 The student is able to create a visual representation to describe how nervous systems transmit information. [See SP 1.1]

LO 3.50 The student is able to create a visual representation to describe how the vertebrate brain integrates information to produce a response. [See SP 1.1] 


\title{
Big Idea 4: Biological systems interact, and these systems and their interactions possess complex properties.
}

\author{
All biological systems are composed of parts that interact with each other. These \\ interactions result in characteristics not found in the individual parts alone. In other \\ words, "the whole is greater than the sum of its parts." All biological systems from the \\ molecular level to the ecosystem level exhibit properties of biocomplexity and diversity. \\ Together, these two properties provide robustness to biological systems, enabling greater \\ resiliency and flexibility to tolerate and respond to changes in the environment. Biological \\ systems with greater complexity and diversity often exhibit an increased capacity to \\ respond to changes in the environment.
}

At the molecular level, the subcomponents of a biological polymer determine the properties of that polymer. At the cellular level, organelles interact with each other as part of a coordinated system that keeps the cell alive, growing and reproducing. The repertory of subcellular organelles and biochemical pathways reflects cell structure and differentiation. Additionally, interactions between external stimuli and gene expression result in specialization and divergence of cells, organs and tissues. Interactions and coordination between organs and organ systems determine essential biological activities for the organism as a whole. External and internal environmental factors can trigger responses in individual organs that, in turn, affect the entire organism. At the population level, as environmental conditions change, community structure changes both physically and biologically. The study of ecosystems seeks to understand the manner in which species are distributed in nature and how they are influenced by their abiotic and biotic interactions, e.g., species interactions. Interactions between living organisms and their environments result in the movement of matter and energy.

Interactions, including competition and cooperation, play important roles in the activities of biological systems. Interactions between molecules affect their structure and function. Competition between cells may occur under conditions of resource limitation. Cooperation between cells can improve efficiency and convert sharing of resources into a net gain in fitness for the organism. Coordination of organs and organ systems provides an organism with the ability to use matter and energy effectively.

Variations in components within biological systems provide a greater flexibility to respond to changes in its environment. Variation in molecular units provides cells with a wider range of potential functions. A population is often measured in terms of genomic diversity and its ability to respond to change. Species with genetic variation and the resultant phenotypes can respond and adapt to changing environmental conditions.

\section{Enduring understanding 4.A: Interactions within biological systems lead to complex properties.}

All biological systems, from cells to ecosystems, are composed of parts that interact with each other. When this happens, the resulting interactions enable characteristics not found 
in the individual parts alone. In other words, "the whole is greater than the sum of its parts," a phenomenon sometimes referred to as "emergent properties."

At the molecular level, the properties of a polymer are determined by its subcomponents and their interactions. For example, a DNA molecule is comprised of a series of nucleotides that can be linked together in various sequences; the resulting polymer carries hereditary material for the cell, including information that controls cellular activities. Other polymers important to life include carbohydrates, lipids and proteins. The interactions between the constituent parts of polymers, their order, their molecular orientation and their interactions with their environment define the structure and function of the polymer.

At the cellular level, organelles interact with each other and their environment as part of a coordinated system that allows cells to live, grow and reproduce. For example, chloroplasts produce trioses through the process of photosynthesis; however, once trioses are synthesized and exported from the chloroplast, they may be packaged by the Golgi body and distributed to the edge of the cell where they serve as a building block for cellulose fibers comprising the cell wall. Similarly, several organelles are involved in the manufacture and export of protein. The repertory of subcellular organelles determines cell structure and differentiation; for instance, the components of plant leaf cells are different from the components of plant root cells, and the components of human liver cells are different from those in the retina. Thus, myriad interactions of different parts at the subcellular level determine the functioning of the entire cell, which would not happen with the activities of individual organelles alone.

In development, interactions between regulated gene expression and external stimuli, such as temperature or nutrient levels or signal molecules, result in specialization of cells, organs and tissues. Differentiation of the germ layers during vertebrate gastrulation is an example of one such divergence. The progression of stem cells to terminal cells can also be explained by the interaction of stimuli and genes. Additionally, cells, organs and tissues may change due to changes in gene expression triggered by internal cues, including regulatory proteins and growth factors, which result in the structural and functional divergence of cells.

Organisms exhibit complex properties due to interactions of their constituent parts, and interactions and coordination between organs and organ systems provide essential biological activities for the organism as a whole. Examples include the vessels and hearts of animals and the roots and shoots of plants. Environmental factors such as temperature can trigger responses in individual organs that, in turn, affect the entire organism.

Interactions between populations within communities also lead to complex properties. As environmental conditions change in time and space, the structure of the community changes both physically and biologically, resulting in a mosaic in the landscape (variety or patterns ) in a community. Communities are comprised of different populations of organisms that interact with each other in either negative or positive ways (e.g., competition, parasitism and mutualism); community ecology seeks to understand 
the manner in which groupings of species are distributed in nature, and how they are influenced by their abiotic environment and species interactions. The physical structure of a community is affected by abiotic factors, such as the depth and flow of water in a stream, and also by the spatial distribution of organisms, such as in the canopy of trees. The mix of species in terms of both the number of individuals and the diversity of species defines the structure of the community. Mathematical or computer models can be used to illustrate and investigate interactions of populations within a community and the effects of environmental impacts on a community. Community change resulting from disturbances sometimes follows a pattern (e.g., succession following a wildfire), and in other cases is random and unpredictable (e.g., founder effect).

At the ecosystem level, interactions among living organisms and with their environment result in the movement of matter and energy. Ecosystems include producers, consumers, decomposers and a pool of organic matter, plus the physiochemical environment that provides the living conditions for the biotic components. Matter, but not energy, can be recycled within an ecosystem via biogeochemical cycles. Energy flows through the system and can be converted from one type to another, e.g., energy available in sunlight is converted to chemical bond energy via photosynthesis. Understanding individual organisms in relation to the environment and the diverse interactions that populations have with one another (e.g., food chains and webs) informs the development of ecosystem models; models allow us to identify the impact of changes in biotic and abiotic factors. Human activities affect ecosystems on local, regional and global scales.

\section{Essential knowledge 4.A.1: The subcomponents of biological molecules} and their sequence determine the properties of that molecule.

a. Structure and function of polymers are derived from the way their monomers are assembled.

Evidence of student learning is a demonstrated understanding of each of the following:

1. In nucleic acids, biological information is encoded in sequences of nucleotide monomers. Each nucleotide has structural components: a five-carbon sugar (deoxyribose or ribose), a phosphate and a nitrogen base (adenine, thymine, guanine, cytosine or uracil). DNA and RNA differ in function and differ slightly in structure, and these structural differences account for the differing functions. [See also 1.D.1, 2.A.3, 3.A.1]

$\mathbf{X}$ The molecular structure of specific nucleotides is beyond the scope of the course and the AP Exam.

2. In proteins, the specific order of amino acids in a polypeptide (primary structure) interacts with the environment to determine the overall shape of the protein, which also involves secondary tertiary and quaternary structure and, thus, its function. The R group of an amino acid can be categorized by chemical properties (hydrophobic, hydrophilic and ionic), and the interactions 
of these $\mathrm{R}$ groups determine structure and function of that region of the protein. [See also 1.D.1, 2.A.3, 2.B.1]

X The molecular structure of specific amino acids is beyond the scope of the course and the AP Exam.

3. In general, lipids are nonpolar; however, phospholipids exhibit structural properties, with polar regions that interact with other polar molecules such as water, and with nonpolar regions where differences in saturation determine the structure and function of lipids. [See also 1.D.1, 2.A.3, 2. B.1]

X The molecular structure of specific lipids is beyond the scope of the course and the AP Exam.

4. Carbohydrates are composed of sugar monomers whose structures and bonding with each other by dehydration synthesis determine the properties and functions of the molecules. Illustrative examples include: cellulose versus starch.

$\mathbf{X}$ The molecular structure of specific carbohydrate polymers is beyond the scope of the course and the AP Exam.

b. Directionality influences structure and function of the polymer.

Evidence of student learning is a demonstrated understanding of each of the following:

1. Nucleic acids have ends, defined by the 3 ' and 5 ' carbons of the sugar in the nucleotide, that determine the direction in which complementary nucleotides are added during DNA synthesis and the direction in which transcription occurs (from 5' to 3'). [See also 3.A.1]

2. Proteins have an amino $\left(\mathrm{NH}_{2}\right)$ end and a carboxyl $(\mathrm{COOH})$ end, and consist of a linear sequence of amino acids connected by the formation of peptide bonds by dehydration synthesis between the amino and carboxyl groups of adjacent monomers.

3. The nature of the bonding between carbohydrate subunits determines their relative orientation in the carbohydrate, which then determines the secondary structure of the carbohydrate.

Learning Objectives:

LO 4.1 The student is able to explain the connection between the sequence and the subcomponents of a biological polymer and its properties. [See SP 7.1]

LO 4.2 The student is able to refine representations and models to explain how the subcomponents of a biological polymer and their sequence determine the properties of that polymer. [See SP 1.3] 
LO 4.3 The student is able to use models to predict and justify that changes in the subcomponents of a biological polymer affect the functionality of the molecule. [See SP 6.1, 6.4]

Essential knowledge 4.A.2: The structure and function of subcellular components, and their interactions, provide essential cellular processes.

a. Ribosomes are small, universal structures comprised of two interacting parts: ribosomal RNA and protein. In a sequential manner, these cellular components interact to become the site of protein synthesis where the translation of the genetic instructions yields specific polypeptides. [See also 2.B.3]

b. Endoplasmic reticulum (ER) occurs in two forms: smooth and rough. [See also 2.B.3]

Evidence of student learning is a demonstrated understanding of each of the following:

1. Rough endoplasmic reticulum functions to compartmentalize the cell, serves as mechanical support, provides site-specific protein synthesis with membrane-bound ribosomes and plays a role in intracellular transport.

2. In most cases, smooth ER synthesizes lipids.

X Specific functions of smooth ER in specialized cells are beyond the scope of the course and the AP Exam.

c. The Golgi complex is a membrane-bound structure that consists of a series of flattened membrane sacs (cisternae). [See also 2.B.3]

Evidence of student learning is a demonstrated understanding of the following:

1. Functions of the Golgi include synthesis and packaging of materials (small molecules) for transport (in vesicles), and production of lysosomes.

$\mathbf{X}$ The role of this organelle in specific phospholipid synthesis and the packaging of enzymatic contents of lysosomes, peroxisomes and secretory vesicles are beyond the scope of the course and the AP Exam.

d. Mitochondria specialize in energy capture and transformation.

[See also 2.A.2, 2.B.3]

Evidence of student learning is a demonstrated understanding of each of the following:

1. Mitochondria have a double membrane that allows compartmentalization within the mitochondria and is important to its function.

2. The outer membrane is smooth, but the inner membrane is highly convoluted, forming folds called cristae.

3. Cristae contain enzymes important to ATP production; cristae also increase the surface area for ATP production. 
e. Lysosomes are membrane-enclosed sacs that contain hydrolytic enzymes, which are important in intracellular digestion, the recycling of a cell's organic materials and programmed cell death (apoptosis). Lysosomes carry out intracellular digestion in a variety of ways. [See also 2.B.3]

X Specific examples of how lysosomes carry out intracellular digestion are beyond the scope of the course and the AP Exam.

f. A vacuole is a membrane-bound sac that plays roles in intracellular digestion and the release of cellular waste products. In plants, a large vacuole serves many functions, from storage of pigments or poisonous substances to a role in cell growth. In addition, a large central vacuole allows for a large surface area to volume ratio. [See also 2. A.3, 2.B.3]

g. Chloroplasts are specialized organelles found in algae and higher plants that capture energy through photosynthesis. [See also 2.A.2, 2 B.3]

Evidence of student learning is a demonstrated understanding of each of the following:

1. The structure and function relationship in the chloroplast allows cells to capture the energy available in sunlight and convert it to chemical bond energy via photosynthesis.

2. Chloroplasts contain chlorophylls, which are responsible for the green color of a plant and are the key light-trapping molecules in photosynthesis. There are several types of chlorophyll, but the predominant form in plants is chlorophyll $a$.

$\mathbf{X}$ The molecular structure of chlorophyll a is beyond the scope of the course and the AP Exam.

3. Chloroplasts have a double outer membrane that creates a compartmentalized structure, which supports its function. Within the chloroplasts are membrane-bound structures called thylakoids. Energycapturing reactions housed in the thylakoids are organized in stacks, called "grana," to produce ATP and $\mathrm{NADPH}_{2}$, which fuel carbon-fixing reactions in the Calvin-Benson cycle. Carbon fixation occurs in the stroma, where molecules of $\mathrm{CO}_{2}$ are converted to carbohydrates.

\section{Learning Objectives:}

LO 4.4 The student is able to make a prediction about the interactions of subcellular organelles. [See SP 6.4]

LO 4.5 The student is able to construct explanations based on scientific evidence as to how interactions of subcellular structures provide essential functions. [See SP 6.2]

LO 4.6 The student is able to use representations and models to analyze situations qualitatively to describe how interactions of subcellular structures, which possess specialized functions, provide essential functions. [See SP 1.4] 
Essential knowledge 4.A.3: Interactions between external stimuli and regulated gene expression result in specialization of cells, tissues and organs.

a. Differentiation in development is due to external and internal cues that trigger gene regulation by proteins that bind to DNA. [See also 3.B.1, 3. B.2]

b. Structural and functional divergence of cells in development is due to expression of genes specific to a particular tissue or organ type. [See also 3.B.1, 3.B.2]

c. Environmental stimuli can affect gene expression in a mature cell. [See also 3.B.1, 3.B.2]

Learning Objective:

LO 4.7 The student is able to refine representations to illustrate how interactions between external stimuli and gene expression result in specialization of cells, tissues and organs. [See SP 1.3]

Essential knowledge 4.A.4: Organisms exhibit complex properties due to interactions between their constituent parts.

a. Interactions and coordination between organs provide essential biological activities.

To foster student understanding of this concept, instructors can choose an illustrative example such as:

- Stomach and small intestines

- Kidney and bladder

- Root, stem and leaf

b. Interactions and coordination between systems provide essential biological activities. To foster student understanding of this concept, instructors can choose an illustrative example such as:

- Respiratory and circulatory

- Nervous and muscular

- Plant vascular and leaf

Learning Objectives:

LO 4.8 The student is able to evaluate scientific questions concerning organisms that exhibit complex properties due to the interaction of their constituent parts. [See SP 3.3] 
LO 4.9 The student is able to predict the effects of a change in a component(s) of a biological system on the functionality of an organism(s). [See SP 6.4]

LO 4.10 The student is able to refine representations and models to illustrate biocomplexity due to interactions of the constituent parts.[See SP 1.3]

Essential knowledge 4.A.5: Communities are composed of populations of organisms that interact in complex ways.

a. The structure of a community is measured and described in terms of species composition and species diversity.

b. Mathematical or computer models are used to illustrate and investigate population interactions within and environmental impacts on a community. [See also 3.E.1,

3.E.3]

To foster student understanding of this concept, instructors can choose an illustrative example such as:

- Predator/prey relationships spreadsheet model

- Symbiotic relationship

- Graphical representation of field data

- Introduction of species

- Global climate change models

c. Mathematical models and graphical representations are used to illustrate population growth patterns and interactions.

Evidence of student learning is a demonstrated understanding of each of the following:

1. Reproduction without constraints results in the exponential growth of a population.

2. A population can produce a density of individuals that exceeds the system's resource availability.

3. As limits to growth due to density-dependent and density-independent factors are imposed, a logistic growth model generally ensues.

4. Demographics data with respect to age distributions and fecundity can be used to study human populations. 
Learning Objectives:

LO 4.11 The student is able to justify the selection of the kind of data needed to answer scientific questions about the interaction of populations within communities. [See SP 1.4, 4.1]

LO 4.12 The student is able to apply mathematical routines to quantities that describe communities composed of populations of organisms that interact in complex ways. [See SP 2.2]

LO 4.13 The student is able to predict the effects of a change in the community's populations on the community. [See SP 6.4]

Essential knowledge 4.A.6: Interactions among living systems and with their environment result in the movement of matter and energy.

a. Energy flows, but matter is recycled. [See also 2.A.1]

b. Changes in regional and global climates and in atmospheric composition influence patterns of primary productivity.

c. Organisms within food webs and food chains interact. [See also 2.D.1]

d. Food webs and food chains are dependent on primary productivity.

e. Models allow the prediction of the impact of change in biotic and abiotic factors. Evidence of student learning is a demonstrated understanding of each of the following:

1. Competition for resources and other factors limits growth and can be described by the logistic model.

2. Competition for resources, territoriality, health, predation, accumulation of wastes and other factors contribute to density-dependent population regulation.

f. Human activities impact ecosystems on local, regional and global scales. [See also 2.D.3]

Evidence of student learning is a demonstrated understanding of each of the following:

1. As human populations have increased in numbers, their impact on habitats for other species have been magnified.

2. In turn, this has often reduced the population size of the affected species and resulted in habitat destruction and, in some cases, the extinction of species.

g. Many adaptations of organisms are related to obtaining and using energy and matter in a particular environment. [See also 2.A.1, 2.A.2] 
Learning Objectives:

LO 4.14 The student is able to apply mathematical routines to quantities that describe interactions among living systems and their environment, which result in the movement of matter and energy. [See SP 2.2]

LO 4.15 The student is able to use visual representations to analyze situations or solve problems qualitatively to illustrate how interactions among living systems and with their environment result in the movement of matter and energy. [See SP 1.4]

LO 4.16 The student is able to predict the effects of a change of matter or energy availability on communities. [See SP 6.4]

\section{Enduring understanding 4.B: Competition and cooperation are important aspects of biological systems.}

Competition and cooperation play important roles in the activities of biological systems at all levels of organization. Living systems require a myriad of chemical reactions on a constant basis, and each of these chemical reactions relies on the cooperation between a particular enzyme and specific substrates, coenzymes and cofactors. Chemical inhibitors may compete for the active sites of enzymes that, in turn, affect the ability of the enzyme to catalyze its chemical reactions. Thus, interactions between molecules affect their structure and function. Other examples of this phenomenon include receptor-ligand interactions and changes in protein structure due to amino acid sequence.

Similar cells may compete with each other when resources are limited; for example, organisms produce many more spores or seeds than will germinate. Competition for resources also determines which organisms are successful and produce offspring. In the vertebrate immune system, competition via antigen-binding sites determines which B-cell lineages are stimulated to reproduce.

The cooperation of parts extends to the organism that depends on the coordination of organs and organ systems, such as between the digestive and excretory systems of an animal or the roots and shoots of a plant. Cooperation within organisms increases efficiency in the use of matter and energy. For example, without the coordination and cooperation of its shoot and roots, a plant would be unable to survive if its root system was too small to absorb water to replace the water lost through transpiration by the shoot. Similarly, exchange of oxygen and carbon dioxide in an animal depends on the functioning of the respiratory and circulatory systems. Furthermore, population interactions influence patterns of species distribution and abundance, and global distribution of ecosystems changes substantially over time.

\section{Essential knowledge 4.B.1: Interactions between molecules affect their structure and function.}

a. Change in the structure of a molecular system may result in a change of the function of the system. [See also 3.D.3] 
b. The shape of enzymes, active sites and interaction with specific molecules are essential for basic functioning of the enzyme.

Evidence of student learning is a demonstrated understanding of each of the following:

1. For an enzyme-mediated chemical reaction to occur, the substrate must be complementary to the surface properties (shape and charge) of the active site. In other words, the substrate must fit into the enzyme's active site.

2. Cofactors and coenzymes affect enzyme function; this interaction relates to a structural change that alters the activity rate of the enzyme. The enzyme may only become active when all the appropriate cofactors or coenzymes are present and bind to the appropriate sites on the enzyme.

X No specific cofactors or coenzymes are within the scope of the course and the AP Exam.

c. Other molecules and the environment in which the enzyme acts can enhance or inhibit enzyme activity. Molecules can bind reversibly or irreversibly to the active or allosteric sites, changing the activity of the enzyme.

d. The change in function of an enzyme can be interpreted from data regarding the concentrations of product or substrate as a function of time. These representations demonstrate the relationship between an enzyme's activity, the disappearance of substrate, and/or presence of a competitive inhibitor.

Learning Objective:

LO 4.17 The student is able to analyze data to identify how molecular interactions affect structure and function. [See SP 5.1]

Essential knowledge 4.B.2: Cooperative interactions within organisms promote efficiency in the use of energy and matter.

a. Organisms have areas or compartments that perform a subset of functions related to energy and matter, and these parts contribute to the whole.

[See also 2.A.2, 4.A.2]

Evidence of student learning is a demonstrated understanding of each of the following:

1. At the cellular level, the plasma membrane, cytoplasm and, for eukaryotes, the organelles contribute to the overall specialization and functioning of the cell.

2. Within multicellular organisms, specialization of organs contributes to the overall functioning of the organism. 
To foster student understanding of this concept, instructors can choose an illustrative example such as:

- Exchange of gases

- Circulation of fluids

- Digestion of food

- Excretion of wastes

3. Interactions among cells of a population of unicellular organisms can be similar to those of multicellular organisms, and these interactions lead to increased efficiency and utilization of energy and matter.

To foster student understanding of this concept, instructors can choose an illustrative example such as:

- Bacterial community in the rumen of animals

- Bacterial community in and around deep sea vents

Learning Objective:

LO 4.18 The student is able to use representations and models to analyze how cooperative interactions within organisms promote efficiency in the use of energy and matter. [See SP 1.4]

Essential knowledge 4.B.3: Interactions between and within populations influence patterns of species distribution and abundance.

a. Interactions between populations affect the distributions and abundance of populations.

Evidence of student learning is a demonstrated understanding of each of the following:

1. Competition, parasitism, predation, mutualism and commensalism can affect population dynamics.

2. Relationships among interacting populations can be characterized by positive and negative effects, and can be modeled mathematically (predator/prey, epidemiological models, invasive species).

3. Many complex symbiotic relationships exist in an ecosystem, and feedback control systems play a role in the functioning of these ecosystems.

X Specific symbiotic interactions are beyond the scope of the course and the AP Exam.

b. A population of organisms has properties that are different from those of the 
individuals that make up the population. The cooperation and competition between individuals contributes to these different properties.

c. Species-specific and environmental catastrophes, geological events, the sudden influx/ depletion of abiotic resources or increased human activities affect species distribution and abundance. [See also 1.A.1, 1.A.2]

To foster student understanding of this concept, instructors can choose an illustrative example such as:

- Loss of keystone species

- Kudzu

- Dutch elm disease

\section{Learning Objective:}

LO 4.19 The student is able to use data analysis to refine observations and measurements regarding the effect of population interactions on patterns of species distribution and abundance. [See SP 5.2]

\section{Essential knowledge 4.B.4: Distribution of local and global ecosystems} changes over time.

a. Human impact accelerates change at local and global levels. [See also 1.A.2]

To foster student understanding of this concept, instructors can choose an illustrative example such as:

- Logging, slash and burn agriculture, urbanization, monocropping, infrastructure development (dams, transmission lines, roads), and global climate change threaten ecosystems and life on Earth.

- An introduced species can exploit a new niche free of predators or competitors, thus exploiting new resources.

- Introduction of new diseases can devastate native species. Illustrative examples include:

- Dutch elm disease

- Potato blight

- Small pox [historic example for Native Americans]

b. Geological and meteorological events impact ecosystem distribution. Evidence of student learning is a demonstrated understanding of the following:

1. Biogeographical studies illustrate these changes. 
To foster student understanding of this concept, instructors can choose an illustrative example such as:

- El Niño

- Continental drift

- Meteor impact on dinosaurs

Learning Objectives:

LO 4.20 The student is able to explain how the distribution of ecosystems changes over time by identifying large-scale events that have resulted in these changes in the past. [See SP 6.3]

LO 4.21 The student is able to predict consequences of human actions on both local and global ecosystems. [See SP 6.4]

\section{Enduring understanding 4.C: Naturally occurring diversity among and between components within biological systems affects interactions with the environment.}

A biological system that possesses many different components often has greater flexibility to respond to changes in its environment. This phenomenon is sometimes referred to as "robustness." Variation in molecular units provides cells with a wider range of functions; cells with multiple copies of genes or heterozygous genes possess a wider range of functions compared to cells with less genetic diversity, while cells with myriad enzymes can catalyze myriad chemical reactions.

Environmental factors influence the phenotypic expression of an organism's genotype. In humans, weight and height are examples of complex traits that can be influenced by environmental conditions. However, even simple single gene traits can be influenced by the environment; for example, flower color in some species of plants is dependent upon the $\mathrm{pH}$ of the environment. Some organisms possess the ability to respond flexibly to environmental signals to yield phenotypes that allow them to adapt to changes in the environment in which they live. Environmental factors such as temperature or density can affect sex determination in some animals, while parthenogenesis can be triggered by reproductive isolation. Plant seed dormancy can increase the survival of a species, and some viruses possess both lysogenic and lytic life cycles.

The level of variation in a population affects its dynamics. The ability of a population to respond to a changing environment (fitness) is often measured in terms of genomic diversity. Species with little genetic diversity, such as a population of plants that reproduces asexually or a very small population exhibiting a genetic bottleneck effect, are at risk with regard to long-term success and survival. Diversity of species within an ecosystem may influence the stability of the ecosystem. Ecosystems with little species diversity are often less resilient to changes in the 
environment. Keystone species, predators, and essential abiotic and biotic factors contribute to maintaining the diversity of an ecosystem. For example, the removal of sea otters or mollusks can drastically affect a marine ecosystem, and the introduction of an exotic plant or animal species can likewise affect the stability of a terrestrial ecosystem.

Essential knowledge 4.C.1: Variation in molecular units provides cells with a wider range of functions.

a. Variations within molecular classes provide cells and organisms with a wider range of functions. [See also 2.B.1, 3.A.1, 4.A.1, 4.A.2]

To foster student understanding of this concept, instructors can choose an illustrative example such as:

- Different types of phospholipids in cell membranes

- Different types of hemoglobin

- $\mathrm{MHC}$ proteins

- Chlorophylls

- Molecular diversity of antibodies in response to an antigen

b. Multiple copies of alleles or genes (gene duplication) may provide new phenotypes. [See also 3.A.4, 3.C.1]

Evidence of student learning is a demonstrated understanding of each of the following:

1. A heterozygote may be a more advantageous genotype than a homozygote under particular conditions, since with two different alleles, the organism has two forms of proteins that may provide functional resilience in response to environmental stresses.

2. Gene duplication creates a situation in which one copy of the gene maintains its original function, while the duplicate may evolve a new function. To foster student understanding of this concept, instructors can choose an illustrative example such as:

- The antifreeze gene in fish

Learning Objective:

LO 4.22 The student is able to construct explanations based on evidence of how variation in molecular units provides cells with a wider range of functions. [See SP 6.2]

Essential knowledge 4.C.2: Environmental factors influence the expression of the genotype in an organism.

a. Environmental factors influence many traits both directly and indirectly.

[See also 3.B.2, 3.C.1] 
To foster student understanding of this concept, instructors can choose an illustrative example such as:

- Height and weight in humans

- Flower color based on soil pH

- Seasonal fur color in arctic animals

- Sex determination in reptiles

- Density of plant hairs as a function of herbivory

- Effect of adding lactose to a Lac + bacterial culture

- Effect of increased UV on melanin production in animals

- Presence of the opposite mating type on pheromones production in yeast and other fungi

b. An organism's adaptation to the local environment reflects a flexible response of its genome.

To foster student understanding of this concept, instructors can choose an illustrative example such as:

- Darker fur in cooler regions of the body in certain mammal species

- Alterations in timing of flowering due to climate changes

Learning Objectives:

LO 4.23 The student is able to construct explanations of the influence of environmental factors on the phenotype of an organism. [See SP 6.2]

LO 4.24 The student is able to predict the effects of a change in an environmental factor on the genotypic expression of the phenotype. [See SP 6.4]

Essential knowledge 4.C.3: The level of variation in a population affects population dynamics.

a. Population ability to respond to changes in the environment is affected by genetic diversity. Species and populations with little genetic diversity are at risk for extinction. [See also 1.A.1, 1.A.2, 1.C.1]

To foster student understanding of this concept, instructors can choose an illustrative example such as:

- California condors

- Black-footed ferrets

- Prairie chickens

- Potato blight causing the potato famine 
- Corn rust affects on agricultural crops

- Tasmanian devils and infectious cancer

b. Genetic diversity allows individuals in a population to respond differently to the same changes in environmental conditions.

To foster student understanding of this concept, instructors can choose an illustrative example such as:

- Not all animals in a population stampede.

- Not all individuals in a population in a disease outbreak are equally affected; some may not show symptoms, some may have mild symptoms, or some may be naturally immune and resistant to the disease.

c. Allelic variation within a population can be modeled by the Hardy-Weinberg equation(s). [See also 1.A.1]

Learning Objectives:

LO 4.25 The student is able to use evidence to justify a claim that a variety of phenotypic responses to a single environmental factor can result from different genotypes within the population. [See SP 6.1]

LO 4.26 The student is able to use theories and models to make scientific claims and/or predictions about the effects of variation within populations on survival and fitness. [See SP 6.4]

Essential knowledge 4.C.4: The diversity of species within an ecosystem may influence the stability of the ecosystem.

a. Natural and artificial ecosystems with fewer component parts and with little diversity among the parts are often less resilient to changes in the environment. [See also 1.C.1]

b. Keystone species, producers, and essential abiotic and biotic factors contribute to maintaining the diversity of an ecosystem. The effects of keystone species on the ecosystem are disproportionate relative to their abundance in the ecosystem, and when they are removed from the ecosystem, the ecosystem often collapses.

Learning Objective:

LO 4.27 The student is able to make scientific claims and predictions about how species diversity within an ecosystem influences ecosystem stability. [See SP 6.4] 


\section{Science Practices for $\mathrm{AP}^{\circledR}$ Biology}

\section{Science Practice 1: The student can use representations and models to communicate scientific phenomena and solve scientific problems.}

Visual representations and models are indispensable tools for learning and exploring scientific concepts and ideas. The student is able to create representations and models using verbal or written explanations that describe biological processes. The student also can use representations and models to illustrate biological processes and concepts; communicate information; make predictions; and describe systems to promote and document understanding. Illustrative examples of representations and models are diagrams describing the relationship between photosynthesis and cellular respiration; the structure and functional relationships of membranes; and diagrams that illustrate chromosome movement in mitosis and meiosis. Using model kits, the student can build three-dimensional representations of organic functional groups, carbohydrates, lipids, proteins and nucleic acids. The student is able to demonstrate how chemical structures, such as the Watson and Crick model for DNA, link structure to function at the molecular level and can relate key elements of a process or structure across multiple representations, such as a schematic two-dimensional diagram and a space-filling model of DNA. The student can refine and/or revise visual representations of biological processes, including energy flow through ecosystems; immunological processes; movement of molecules in and out of cells; and graphs or other visual data representations of experimental results. The student can use/apply representations and models to make predictions and address scientific questions as well as interpret and create graphs drawn from experimental data.

1.1 The student can create representations and models of natural or man-made phenomena and systems in the domain.

1.2 The student can describe representations and models of natural or man-made phenomena and systems in the domain.

1.3 The student can refine representations and models of natural or man-made phenomena and systems in the domain.

1.4 The student can use representations and models to analyze situations or solve problems qualitatively and quantitatively.

1.5 The student can reexpress key elements of natural phenomena across multiple representations in the domain. 


\section{Science Practice 2: The student can use mathematics appropriately.}

The student can routinely use mathematics to solve problems, analyze experimental data, describe natural phenomena, make predictions, and describe processes symbolically. The student also can justify the selection of a particular mathematical routine and apply the routine to describe natural phenomena. The student is able to estimate the answers to quantitative questions using simplifying assumptions and to use this information to help describe and understand natural phenomena. Examples of the use of mathematics in biology include, but are not limited to, the use of Chi-square in analyzing observed versus predicted inherited patterns; determination of mean and median; use of the HardyWeinberg equation to predict changes in gene frequencies in a population; measurements of concentration gradients and osmotic potential; and determination of the rates of chemical reactions, processes and solute concentrations. The student is able to measure and collect experimental data with respect to volume, size, mass, temperature, $\mathrm{pH}$, etc. In addition, the student can estimate energy procurement and utilization in biological systems, including ecosystems.

2.1 The student can justify the selection of a mathematical routine to solve problems.

2.2 The student can apply mathematical routines to quantities that describe natural phenomena.

2.3 The student can estimate numerically quantities that describe natural phenomena.

\section{Science Practice 3: The student can engage in scientific questioning to extend thinking or to guide investigations within the context of the AP course.}

As scientists and students, how do we know what we know? Facts, concepts and theories fill biology textbooks, but how did scientists discover facts, concepts and theories that make up modern science, such as that cells produce carbon dioxide as a by-product of respiration or that the details for copying the two strands of DNA differ during replication? What historical experiments provided evidence that DNA, not protein, was the hereditary material for living organisms? What scientific evidence supports evolution by natural selection, and how is this different than alternative ideas with respect to evolution and origin of life? To provide deeper understanding of the concepts, the student must be able to answer, "How do we know what we know?" with, "This is why we know what we know." The student is able to pose, refine and evaluate scientific questions about natural phenomena and investigate answers through experimentation, research, and information gathering and discussion. For example, if the student poses the question: "What happens to photosynthesis at very high, nonbiological temperatures?" he or she can address this question in a variety of means: literature searches, fact finding and/or designing an experiment to investigate the effect of temperature on chloroplast function, 
including collecting data, making predictions, drawing conclusions and refining the original question or approaches. The student is able to formulate good scientific questions - ones that are amenable to experimental approaches and addressable through evidence - and can distinguish them from other questions that are ethical, social or teleological in nature. The student can pose and rationally discuss questions that address ethical and civic issues that surround the development and application of scientific knowledge, and controversial issues such as stem cells, cloning, genetically modified organisms, and who should decide what types of biological research are acceptable and which are not.

3.1 The student can pose scientific questions.

3.2 The student can refine scientific questions.

3.3 The student can evaluate scientific questions.

\section{Science Practice 4: The student can plan and implement data collection strategies appropriate to a particular scientific question.}

Experimentation and the collection and analysis of scientific evidence are at the heart of biology. Data can be collected from many different sources: experimental investigation, scientific observation, the findings of others, historic reconstruction and archival records. After the student poses a question about biology, he or she is able to investigate and arrive at answers through experimentation and reasoning. In this coupled process, the student can justify the selection of the kind of data needed to answer a question. For example, if the question is about how temperature affects enzymatic activity, the student should be able to collect data about temperature while controlling other variables, such as $\mathrm{pH}$ and solute concentration. To test a hypothesis about an observation, the student is able to design an experiment; identify needed controls; identify needed supplies and equipment from a given list of resources; develop or follow an experimental protocol to collect data; analyze data and draw conclusions from the results; and describe the limitations of the experiment and conclusions. In addition, the student can draw conclusions from experimental results of other scientists, e.g., the historical experiments of Fredrick Griffith, Calvin and Krebs, Hershey and Chase, and Watson and Crick.

4.1 The student can justify the selection of the kind of data needed to answer a particular scientific question.

4.2 The student can design a plan for collecting data to answer a particular scientific question.

4.3 The student can collect data to answer a particular scientific question.

4.4 The student can evaluate sources of data to answer a particular scientific question. 


\section{Science Practice 5: The student can perform data analysis and evaluation of evidence.}

The student can analyze data collected from an experimental procedure or from a given source to determine whether the data support or does not support a conclusion or hypothesis. For example, if the student conducts an experiment to determine if light intensity affects the rate of photosynthesis, he or she can construct a graph based on the collected data and use the graph to formulate statements, conclusions, and possibly a hypothesis. Alternatively, the student can draw conclusions from a provided data set. For example, given a graph depicting the percent change in the mass of potato cores after exposure to different concentrations of sucrose, the student is able to estimate the concentration of sucrose within the potato core. The student also is able to assess the validity of experimental evidence. Using the same example, if given hypothetical data showing that potato cores increase in mass when placed in solutions with lower water potential (a hypertonic solution), the student is able to explain why the data (evidence) are likely invalid: Since potatoes contain sucrose, they should increase in mass only when placed in solutions with higher water potential (hypotonic). After identifying possible sources of error in an experimental procedure or data set, the student can then revise the protocol to obtain more valid results. When presented with a range of data, the student is able to identify outliers and propose an explanation for them as well as a rationale for how they should be dealt with.

5.1 The student can analyze data to identify patterns or relationships.

5.2 The student can refine observations and measurements based on data analysis.

5.3 The student can evaluate the evidence provided by data sets in relation to a particular scientific question.

\section{Science Practice 6: The student can work with scientific explanations and theories.}

The student can work with scientific descriptions, explanations and theories that describe biological phenomena and processes. In efforts to answer, "How do we know what we know?" the student can call upon current knowledge and historical experiments, and draw inferences from his or her explorations to justify claims with evidence. For example, the student is able to cite evidence drawn from the different scientific disciplines that supports natural selection and evolution, such as the geological record, antibiotic-resistance in bacteria, herbicide resistance in plants or how a population bottleneck changes HardyWeinberg Equilibrium. The student can articulate through narrative or annotated visual representation how scientific explanations are refined or revised with the acquisition of new information based on experimentation; for example, the student can describe/explain how advances in molecular genetics made possible a deeper understanding of how genes are carried in DNA and of how genes are expressed to determine phenotypes. The student 
understands that new scientific discoveries often depend on advances in technology; for example, only when microscopy was sufficiently advanced could the linkage between chromosomes and the transmission of genetic traits be clearly established. Likewise, the ability to sequence whole genomes allows comparisons between the entire genetic information in different species, and technology is revealing the existence of many previously unknown genes and evolutionary relationships. In addition, the student can use existing knowledge and models to make predictions. For example, when provided a sequence of DNA containing a designated mutational change, the student can predict the effect of the mutation on the encoded polypeptide and propose a possible resulting phenotype. The student also can evaluate the merits of alternative scientific explanations or conclusions.

6.1 The student can justify claims with evidence.

6.2 The student can construct explanations of phenomena based on evidence produced through scientific practices.

6.3 The student can articulate the reasons that scientific explanations and theories are refined or replaced.

6.4 The student can make claims and predictions about natural phenomena based on scientific theories and models.

6.5 The student can evaluate alternative scientific explanations.

\section{Science Practice 7: The student is able to connect and relate knowledge across various scales, concepts and representations in and across domains.}

The student is able to describe through narrative and/or annotated visual representation how biological processes are connected across various scales such as time, size and complexity. For example, DNA sequences, metabolic processes and morphological structures that arise through evolution connect the organisms that compose the tree of life, and the student should be able to use various types of phylogenetic trees/cladograms to show connections and ancestry, and to describe how natural selection explains biodiversity. Examples of other connections are photosynthesis at the cellular level and environmental carbon cycling; biomass generation and climate change; molecular and macroevolution; the relation of genotype to phenotype and natural selection; cell signaling pathways and embryonic development; bioenergetics and microbial ecology; and competition and cooperation from molecules to populations. The student is able to describe how enduring understandings are connected to other enduring understandings, to a big idea, and how the big ideas in biology connect to one another and to other disciplines. The student draws on information from other sciences to explain biological processes; examples include how the conservation of energy affects biological systems; why lipids are nonpolar and insoluble in water; why water exhibits cohesion and adhesion, 
and why molecules spontaneously move from high concentration to areas of lower concentration, but not vice versa.

7.1 The student can connect phenomena and models across spatial and temporal scales.

7.2 The student can connect concepts in and across domain(s) to generalize or extrapolate in and/or across enduring understandings and/or big ideas. 


\section{References}

The AP course and exam development process relies on groups of nationally renowned subject-matter experts in each discipline, including professionals in secondary and postsecondary education as well as from professional organizations. These experts ensure that AP courses and exams reflect the most up-to-date information available, that the courses and exams are appropriate for a college-level course, and that student proficiency is assessed properly. To help ensure that the knowledge, skills and abilities identified in the course and exam are articulated in a manner that will serve as a strong foundation for both curriculum and assessment design, the subject-matter experts for AP Biology utilized principles and tools from the following works.

Mislevy, R. J., and M. M. Riconscente. 2005. Evidence-Centered Assessment Design: Layers, Structures, and Terminology (PADI Technical Report 9). Menlo Park, CA: SRI International and University of Maryland. Retrieved May 1, 2006, from http://padi.sri.com/downloads/TR9_ECD.pdf.

Riconscente, M. M., R. J. Mislevy, and L. Hamel. 2005. An Introduction to PADI Task Templates (PADI Technical Report 3). Menlo Park, CA: SRI International and University of Maryland. Retrieved May 1, 2006, from http://padi.sri.com/downloads/TR3_Templates.pdf.

Steinberg, L. S., et al. 2003. Introduction to the Biomass Project: An Illustration of Evidence-Centered Assessment Design and Delivery Capability (CRESST Technical Report 609). Los Angeles: Center for the Study of Evaluation, CRESST, UCLA.

Wiggins, G., and J. McTighe. 2005. Understanding by Design. 2nd ed. Alexandria, VA: Association for Supervision and Curriculum Development. 


\section{Appendix}

\section{AP Biology Concepts at a Glance}

\section{Big Idea 1:The process of evolution drives the diversity and unity of life.}

\begin{tabular}{|c|c|}
\hline \multirow[t]{4}{*}{$\begin{array}{l}\text { Enduring understanding 1.A: Change in the genetic makeup } \\
\text { of a population over time is evolution. }\end{array}$} & $\begin{array}{l}\text { Essential knowledge 1.A.1: Natural selection is a major } \\
\text { mechanism of evolution. }\end{array}$ \\
\hline & $\begin{array}{l}\text { Essential knowledge 1.A.2: Natural selection acts on } \\
\text { phenotypic variations in populations. }\end{array}$ \\
\hline & $\begin{array}{l}\text { Essential knowledge 1.A.3: Evolutionary change is also } \\
\text { driven by random processes. }\end{array}$ \\
\hline & $\begin{array}{l}\text { Essential knowledge 1.A.4: Biological evolution is } \\
\text { supported by scientific evidence from many disciplines, } \\
\text { including mathematics. }\end{array}$ \\
\hline \multirow[t]{2}{*}{$\begin{array}{l}\text { Enduring understanding 1.B: Organisms are linked by lines } \\
\text { of descent from common ancestry. }\end{array}$} & $\begin{array}{l}\text { Essential knowledge 1.B.1: Organisms share many } \\
\text { conserved core processes and features that evolved and } \\
\text { are widely distributed among organisms today. }\end{array}$ \\
\hline & $\begin{array}{l}\text { Essential knowledge 1.B.2: Phylogenetic trees and } \\
\text { cladograms are graphical representations (models) of } \\
\text { evolutionary history that can be tested. }\end{array}$ \\
\hline \multirow[t]{3}{*}{$\begin{array}{l}\text { Enduring understanding 1.C: Life continues to evolve within } \\
\text { a changing environment. }\end{array}$} & $\begin{array}{l}\text { Essential knowledge 1.C.1: Speciation and extinction have } \\
\text { occurred throughout the Earth's history. }\end{array}$ \\
\hline & $\begin{array}{l}\text { Essential knowledge 1.C.2: Speciation may occur when } \\
\text { two populations become reproductively isolated from each } \\
\text { other. }\end{array}$ \\
\hline & $\begin{array}{l}\text { Essential knowledge 1.C.3: Populations of organisms } \\
\text { continue to evolve. }\end{array}$ \\
\hline \multirow[t]{2}{*}{$\begin{array}{l}\text { Enduring understanding 1.D:The origin of living systems is } \\
\text { explained by natural processes. }\end{array}$} & $\begin{array}{l}\text { Essential knowledge 1.D.1:There are several hypotheses } \\
\text { about the natural origin of life on Earth, each with } \\
\text { supporting scientific evidence. }\end{array}$ \\
\hline & $\begin{array}{l}\text { Essential knowledge 1.D.2: Scientific evidence from many } \\
\text { different disciplines supports models of the origin of life. }\end{array}$ \\
\hline
\end{tabular}




\section{Big Idea 2: Biological systems utilize free energy and molecular building blocks to grow, to reproduce and to maintain dynamic homeostasis.}

\begin{tabular}{|l|l}
\hline $\begin{array}{l}\text { Enduring understanding 2.A: Growth, reproduction and } \\
\text { maintenance of the organization of living systems require } \\
\text { free energy and matter. }\end{array}$ & $\begin{array}{l}\text { Essential knowledge 2.A.1: All living systems require } \\
\text { constant input of free energy. }\end{array}$ \\
\hline & $\begin{array}{l}\text { Essential knowledge 2.A.2: Organisms capture and stor } \\
\text { free energy for use in biological processes. }\end{array}$ \\
\hline $\begin{array}{l}\text { Essential knowledge 2.A.3: Organisms must exchange } \\
\text { matter with the environment to grow, reproduce and } \\
\text { maintain organization. }\end{array}$ \\
\hline
\end{tabular}
dynamic homeostasis require that cells create and maintain internal environments that are different from their external environments.
Enduring understanding 2.B: Growth, reproduction and

Essential knowledge 2.B.1: Cell membranes are selectively permeable due to their structure.

Essential knowledge 2.B.2: Growth and dynamic homeostasis are maintained by the constant movement of molecules across membranes.

Essential knowledge 2.B.3: Eukaryotic cells maintain internal membranes that partition the cell into specialized regions.

Enduring understanding 2.C: Organisms use feedback mechanisms to regulate growth and reproduction, and to maintain dynamic homeostasis.

Essential knowledge 2.C.1: Organisms use feedback mechanisms to maintain their internal environments and respond to external environmental changes.

Essential knowledge 2.C.2: Organisms respond to changes in their external environments.
Enduring understanding 2.D: Growth and dynamic homeostasis of a biological system are influenced by changes in the system's environment.

Essential knowledge 2.D.1: All biological systems from cells and organisms to populations, communities and ecosystems are affected by complex biotic and abiotic interactions involving exchange of matter and free energy.

Essential knowledge 2.D.2: Homeostatic mechanisms reflect both common ancestry and divergence due to adaptation in different environments.

Essential knowledge 2.D.3: Biological systems are affected by disruptions to their dynamic homeostasis.

Essential knowledge 2.D.4: Plants and animals have a variety of chemical defenses against infections that affect dynamic homeostasis.

Enduring understanding 2.E: Many biological processes involved in growth, reproduction and dynamic homeostasis include temporal regulation and coordination.
Essential knowledge 2.E.1:Timing and coordination of specific events are necessary for the normal development of an organism, and these events are regulated by a variety of mechanisms.

Essential knowledge 2.E.2:Timing and coordination of physiological events are regulated by multiple mechanisms.

Essential knowledge 2.E.3:Timing and coordination of behavior are regulated by various mechanisms and are important in natural selection. 


\section{Big Idea 3: Living systems store, retrieve, transmit and respond to information essential to life processes.}

\begin{tabular}{|c|c|}
\hline \multirow[t]{4}{*}{$\begin{array}{l}\text { Enduring understanding } 3 . \mathbf{A} \text { : Heritable information } \\
\text { provides for continuity of life. }\end{array}$} & $\begin{array}{l}\text { Essential knowledge } 3 . A .1 \text { : DNA, and in some cases RNA, } \\
\text { is the primary source of heritable information. }\end{array}$ \\
\hline & $\begin{array}{l}\text { Essential knowledge } 3 . A .2 \text { : In eukaryotes, heritable } \\
\text { information is passed to the next generation via processes } \\
\text { that include the cell cycle and mitosis or meiosis plus } \\
\text { fertilization. }\end{array}$ \\
\hline & $\begin{array}{l}\text { Essential knowledge 3.A.3: The chromosomal basis of } \\
\text { inheritance provides an understanding of the pattern of } \\
\text { passage (transmission) of genes from parent to offspring. }\end{array}$ \\
\hline & $\begin{array}{l}\text { Essential knowledge } 3 . A .4: \text { The inheritance pattern of many } \\
\text { traits cannot be explained by simple Mendelian genetics. }\end{array}$ \\
\hline \multirow[t]{2}{*}{$\begin{array}{l}\text { Enduring understanding 3.B: Expression of genetic } \\
\text { information involves cellular and molecular mechanisms. }\end{array}$} & $\begin{array}{l}\text { Essential knowledge 3.B.1: Gene regulation results in } \\
\text { differential gene expression, leading to cell specialization. }\end{array}$ \\
\hline & $\begin{array}{l}\text { Essential knowledge 3.B.2: A variety of intercellular and } \\
\text { intracellular signal transmissions mediate gene expression. }\end{array}$ \\
\hline \multirow[t]{3}{*}{$\begin{array}{l}\text { Enduring understanding 3.C:The processing of genetic } \\
\text { information is imperfect and is a source of genetic variation. }\end{array}$} & $\begin{array}{l}\text { Essential knowledge 3.C.1: Changes in genotype can result } \\
\text { in changes in phenotype. }\end{array}$ \\
\hline & $\begin{array}{l}\text { Essential knowledge 3.C.2: Biological systems have } \\
\text { multiple processes that increase genetic variation. }\end{array}$ \\
\hline & $\begin{array}{l}\text { Essential knowledge 3.C.3: Viral replication results in } \\
\text { genetic variation, and viral infection can introduce genetic } \\
\text { variation into the hosts. }\end{array}$ \\
\hline \multirow[t]{4}{*}{$\begin{array}{l}\text { Enduring understanding 3.D: Cells communicate by } \\
\text { generating, transmitting and receiving chemical signals. }\end{array}$} & $\begin{array}{l}\text { Essential knowledge 3.D.1: Cell communication processes } \\
\text { share common features that reflect a shared evolutionary } \\
\text { history. }\end{array}$ \\
\hline & $\begin{array}{l}\text { Essential knowledge 3.D.2: Cells communicate with each } \\
\text { other through direct contact with other cells or from a } \\
\text { distance via chemical signaling. }\end{array}$ \\
\hline & $\begin{array}{l}\text { Essential knowledge 3.D.3: Signal transduction pathways } \\
\text { link signal reception with cellular response. }\end{array}$ \\
\hline & $\begin{array}{l}\text { Essential knowledge 3.D.4: Changes in signal transduction } \\
\text { pathways can alter cellular response. }\end{array}$ \\
\hline \multirow[t]{2}{*}{$\begin{array}{l}\text { Enduring understanding 3.E: Transmission of information } \\
\text { results in changes within and between biological systems. }\end{array}$} & $\begin{array}{l}\text { Essential knowledge 3.E.1: Individuals can act on } \\
\text { information and communicate it to others. }\end{array}$ \\
\hline & $\begin{array}{l}\text { Essential knowledge 3.E.2: Animals have nervous systems } \\
\text { that detect external and internal signals, transmit and } \\
\text { integrate information, and produce responses. }\end{array}$ \\
\hline
\end{tabular}




\section{Big Idea 4: Biological systems interact, and these systems and their interactions possess complex properties.}

\begin{tabular}{|c|c|}
\hline $\begin{array}{l}\text { Enduring understanding 4.A: Interactions within biological } \\
\text { systems lead to complex properties. }\end{array}$ & $\begin{array}{l}\text { Essential knowledge 4.A.1: The subcomponents of } \\
\text { biological molecules and their sequence determine the } \\
\text { properties of that molecule. }\end{array}$ \\
\hline & $\begin{array}{l}\text { Essential knowledge 4.A.2: The structure and function of } \\
\text { subcellular components, and their interactions, provide } \\
\text { essential cellular processes. }\end{array}$ \\
\hline & $\begin{array}{l}\text { Essential knowledge 4.A.3: Interactions between } \\
\text { external stimuli and regulated gene expression result in } \\
\text { specialization of cells, tissues and organs. }\end{array}$ \\
\hline & $\begin{array}{l}\text { Essential knowledge 4.A.4: Organisms exhibit complex } \\
\text { properties due to interactions between their constituent } \\
\text { parts. }\end{array}$ \\
\hline & $\begin{array}{l}\text { Essential knowledge 4.A.5: Communities are composed of } \\
\text { populations of organisms that interact in complex ways. }\end{array}$ \\
\hline & $\begin{array}{l}\text { Essential knowledge 4.A.6: Interactions among living } \\
\text { systems and with their environment result in the movement } \\
\text { of matter and energy. }\end{array}$ \\
\hline \multirow[t]{4}{*}{$\begin{array}{l}\text { Enduring understanding 4.B: Competition and cooperation } \\
\text { are important aspects of biological systems. }\end{array}$} & $\begin{array}{l}\text { Essential knowledge 4.B.1: Interactions between molecules } \\
\text { affect their structure and function. }\end{array}$ \\
\hline & $\begin{array}{l}\text { Essential knowledge 4.B.2: Cooperative interactions within } \\
\text { organisms promote efficiency in the use of energy and } \\
\text { matter. }\end{array}$ \\
\hline & $\begin{array}{l}\text { Essential knowledge 4.B.3: Interactions between and within } \\
\text { populations influence patterns of species distribution and } \\
\text { abundance. }\end{array}$ \\
\hline & $\begin{array}{l}\text { Essential knowledge 4.B.4: Distribution of local and global } \\
\text { ecosystems changes over time. }\end{array}$ \\
\hline \multirow{4}{*}{$\begin{array}{l}\text { Enduring understanding 4.C: Naturally occurring diversity } \\
\text { among and between components within biological systems } \\
\text { affects interactions with the environment. }\end{array}$} & $\begin{array}{l}\text { Essential knowledge 4.C.1: Variation in molecular units } \\
\text { provides cells with a wider range of functions. }\end{array}$ \\
\hline & $\begin{array}{l}\text { Essential knowledge 4.C.2: Environmental factors influence } \\
\text { the expression of the genotype in an organism. }\end{array}$ \\
\hline & $\begin{array}{l}\text { Essential knowledge 4.C.3: The level of variation in a } \\
\text { population affects population dynamics. }\end{array}$ \\
\hline & $\begin{array}{l}\text { Essential knowledge 4.C.4: The diversity of species within } \\
\text { an ecosystem may influence the stability of the ecosystem. }\end{array}$ \\
\hline
\end{tabular}




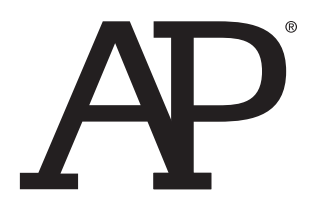

